\title{
2002 MRS Fall Meeting Features Innovations in Materials Research
}

The 2002 Materials Research Society Fall Meeting saw the convergence of disparate fields and technologies such as semiconductor quantum dots, MEMS and NEMS, nanocrystalline semiconductor materials and devices, and 3D nanoengineered assemblies under the umbrella of "Nanomaterials and Technology." Held December 2-6 at the Hynes Convention Center and Sheraton Boston Hotel and Towers in Boston, Massachusetts, the Meeting also ran the thread of molecular electronics, as a virtual symposium, through a number of symposia, as designed by the Meeting Chairs, Marie-Isabelle Baraton (University of Limoges), Eric L. Garfunkel (Rutgers University), David C. Martin (University of Michigan), and Stuart S.P. Parkin (IBM Almaden Research Center). Along with the technical component, the chairs held special events with an emphasis on international collaboration and review presentations that stretched the boundaries of interdisciplinary materials research.

The 38 technical symposia were categorized into clusters, with 2234 oral presentations and 1544 posters. Special events included a series of talks on international research collaboration policy, representing opportunities in the United States, China, Europe, Japan, and South America. Plenary speaker Steven Vogel of Duke University brought out the materials aspects of his work in biological design. An awards ceremony honored Howard K. Birnbaum (University of Illinois) with the Von Hippel Award; Robert W. Cahn (Cambridge University), Turnbull Lecturer; MRS Medalists Uzi Landman (Georgia Institute of Technology) and Charles M. Lieber (Harvard University); and Graduate Student Award recipients. Awards were also given for best poster presentations. Symposium $X$ presented overviews on the "Frontiers of Materials Research," for the nonspecialist, which bridged various disciplines with materials research. MTS Systems Corporation participated in a Research Tool Seminar. See sidebars covering these and other events. The equipment exhibit featured 220 exhibitors from around the world, displaying a range of equipment, services, products, publications, and software.

\section{Technical Talks}

On Sunday, one day before technical sessions began, tutorials were held to introduce a new or breaking area of research, highlight new developments in an established field, or provide an overview for meeting attendees who are unfamiliar with the topic. J.D. Joannopoulos (MIT) introduced the topic of nanophotonics in the tutorial for Symposium O. He said that, in theory, "defects are good things," and proceeded, with instructor D.J. Norris (Univ. of Minnesota) to present the fundamentals of photonic structures and the opportunities they yield through their ability to control the flow of light. The proper choices of materials and architectures are needed to control light, just as doping of semiconductors controls the flow of electrons, they said. Photonic bandgaps can be created by making a lattice of one material in a sea of another material with a very different dielectric constant, for instance, silicon and air. This leads to forbidden states and thus a bandgap. Next, defects are introduced, which act like a force to localize light and control it, reintroducing states into the gap, similar to the way doping is used to designate electronic pathways in the clean slate of a silicon crystal. Light can bend perfectly around corners, and efficient crossings and splitters can be made. It is possible by design to achieve $100 \%$ transmission with photonic crystals. However, such designs require single-mode waveguide operation, symmetry, and 0.5-wavelength increments to get around the bends. Examples of experimental work were given, including colloidal self-assembly, which can be used to make artificial opals, and the advantages and challenges associated with LIGA x-ray lithography, optical interference techniques, glancing angle deposition, and assembly of block copolymers.

A tutorial on lithographic and nonlithographic methods for 3D nanofabrication was given as part of Symposium $\mathrm{H}$ on Sunday afternoon. S. Matsui (Himeji Inst. of Technology, Japan) described the growth of 3D nanostructures by FIB-CVD and mechanical property measurements of these structures. He described the use of
FIB-CVD to create amorphous carbon nanostructures in the design of a wineglass, coils, drills, rods, and a micro "colosseum," suggesting that FIB can be used to create nanostructures with any shape.

In the tutorial for Symposium KK, E. Mazur (Harvard) covered femtosecond techniques. Lasers have progressed from the microsecond pulses of the 1960s, steadily shortening to the $5-6$ fs pulses now available. These shorter pulses make it possible to capture ultrafast phenomena. The high intensity created by squeezing photons in a close space makes it possible to not only probe and learn about phenomena, but to actually manipulate valence electrons which enables manipulation of the structure of matter.

During the technical sessions of Symposium KK, N. Shen (Harvard) described the use of femtosecond laser pulses of a few nanojoules to vaporize mitochondria inside a cell. Multiple laser beams are absorbed through nonlinear processes, leading to a small region of absorption, causing local damage while keeping intact neighboring areas and even the cell wall through which the laser entered. This provides a method for precise and selective microsurgery of subcellular structures in a viable cell.

Symposium II provided an unusual meeting of disciplines in a session devoted to archaeology and nuclear-waste management. H. Römich (Fraunhofer-Institut für Silicatforschung) introduced results on the study of ancient glass by microcomputed $\mathrm{x}$-ray tomography (mCT), a new analysis method. Römich used mCT to study three areas relating to the degradation of archaeological glass: the influence of $\mathrm{pH}$ level of the soil (burial environment), the glass composition, and time. She concluded that the time dependence of the degradation of the model glass is relevant for validating the performance of materials for nuclearwaste management. Römich's studies also showed that a slight difference in the glass composition leads to different alterations, and a slight difference in the $\mathrm{pH}$ level leads to a difference in alteration of the model glass. She said that mechanistic studies are highly effective only in laboratory experiments.

"Nano-ionics has a role in support of sustainable energy," said A. Goossens (Delft Univ. of Technology) in Symposium EE. He described a new generation of 3D 
solar cells formed by depositing CuInS 2 inside pores of nanostructured $\mathrm{TiO}_{2}$ using atomic layer deposition. The resulting structure is not only an active photovoltaic with $11 \%$ energy conversion, but it improves with exposure to light, apparently due to passivation of sulfur vacancies.

One of several facets of nanotechnology that was explored during the course of Symposium DD on solid-state chemistry of inorganic materials concerned the recent development of nanoporous solids. The two exciting new classes of thermally stable porous solids that were described contain transition metals. The nanoporous nickel phosphates, described by T. Cheetham (UCSB), exhibit shape-selective hydrogenation and dehydrogenation catalysis, showing promise for hydrogen storage and gas separations. In contrast to the phosphates, a large new class of transitionmetal silicates, reported by A.J. Jacobson (Univ. of Houston), shows classical zeolitic properties combined with a potential for shape-selective oxidation. These developments underline the evolution of materials that exhibit properties beyond those found in traditional crystalline aluminosilicate molecular sieves.

A.R. Kaul (Moscow State) reported on a survey of ternary oxides. It was demon-

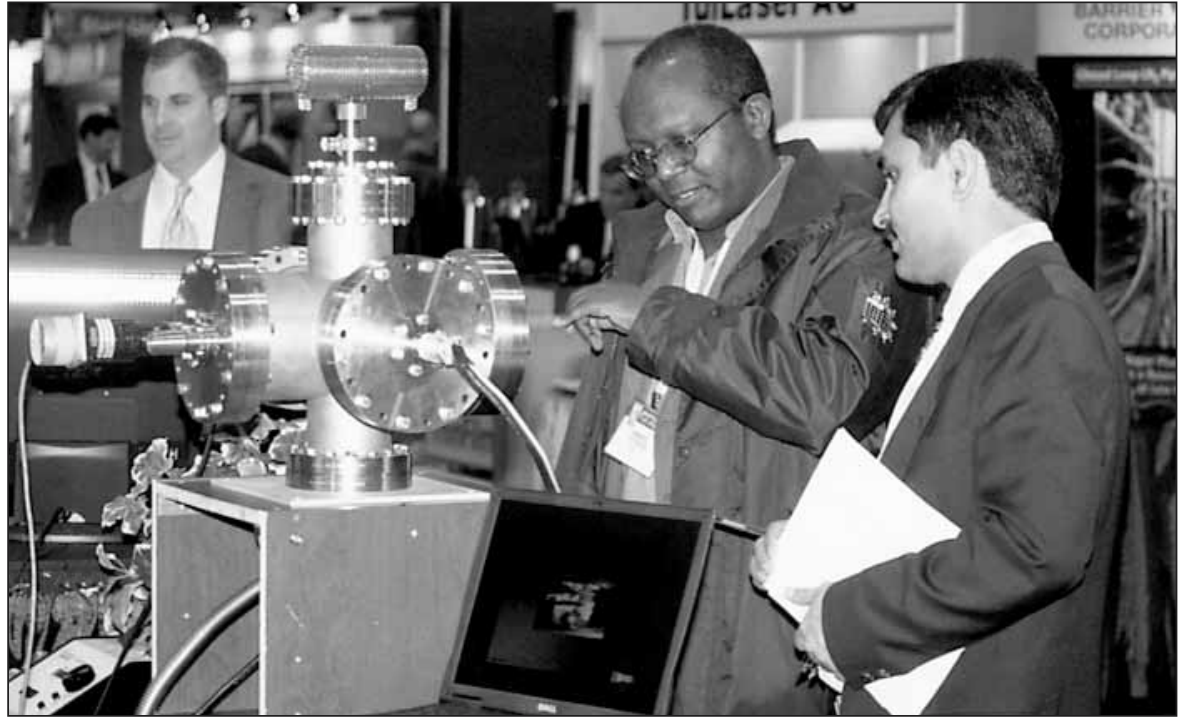

The MRS equipment exhibit featured 220 exhibitors from around the world, displaying a range of equipment, services, products, publications, and software.

strated that using the epitaxy on wellmatched substrates, many compounds that need high pressure, high temperature, or high oxygen partial pressure for their synthesis in the bulk state can be obtained as epitaxial films at much more moderate conditions. Epitaxial stabilization, which was known as the phenomenological base for obtaining the solutions of III-V semiconductors for many appli-

\section{ACRONYM KEY}

1D: one-dimensional

2D: two-dimensional

3D: three-dimensional

ACS: American Chemical Society

AFM: atomic force microscope

AFOSR: Air Force Office of Scientific Research

AFRL: Air Force Research Laboratory

ANL: Argonne National Laboratory

ARL: Army Research Laboratory

ARO: Army Research Office

ASU: Arizona State University

BMG: bulk metallic glass

BST: $(\mathrm{Ba}, \mathrm{Sr}) \mathrm{TiO}_{3}$

Caltech: California Institute of Technology

CMOS: complementary metal oxide semiconductor

CMU: Carnegie Mellon University

CVD: chemical vapor deposition

CWRU: Case Western Reserve University

DARPA: Defense Advanced Research

Projects Agency

DOE: U.S. Department of Energy

DPN: dip-pen nanolithography

DW: direct-write

EELS: electron energy-loss spectroscopy

EPR: electron paramagnetic resonance

FeRAM: ferroelectric random-access memory

FET: field-effect transistor

FIB-CVD: focused ion beam chemical

vapor deposition

FMR: ferromagnetic resonance
GE: General Electric

Georgia Tech: Georgia Institute of Technology

GM: General Motors

GMR: giant magnetoresistance

HTS: high-temperature superconductor

IPF: Institute of Polymer Research Dresden, Germany

LANL: Los Alamos National Laboratory

LBNL: Lawrence Berkeley National Laboratory

LCM: lateral composition modulation

LED: light-emitting diode/device

LEEM: low-energy electron microscopy

LIGA: lithography, electrodeposition, and molding

LSU: Louisiana State University

MBE: molecular-beam epitaxy

mCT: microcomputed x-ray tomography

MEMS: microelectromechanical systems

MFM: magnetic force microscopy

MIT: Massachusetts Institute of Technology

MPI: Max Planck Institute

MRSEC: Materials Research Science and

Engineering Centers

MSE: materials science and engineering

MSL: microstereolithography

NCSU: North Carolina State University

NEMS: nanoelectromechanical systems

NIST: National Institute of Standards

and Technology

NRL: Naval Research Laboratory

NSF: National Science Foundation
NSFC: National Natural Science Foundation of China

NYU: New York University

ONR: Office of Naval Research

ORNL: Oak Ridge National Laboratory

Penn State: The Pennsylvania State University PNNL: Pacific Northwest National Laboratory PSZ: partially stabilized zirconia

PZT: lead zirconium titanate

R\&D: research and development

RAM: random-access memory

RBCO: $\mathrm{RBa}_{2} \mathrm{Cu}_{3} \mathrm{O}_{7}$

rf: radio frequency

RP: rapid prototyping

RPI: Rensselaer Polytechnic Institute

SFF: solid freeform

SMM: single-molecule magnet

SNL: Sandia National Laboratories

STEM: scanning transmission electron

microscopy

STM: scanning tunneling microscopy

STS: scanning tunneling spectroscopy

SUNY: State University of New York

TBC: thermal-barrier coating

TCO: transparent conducting oxide

UC: University of California

UCSB: University of California-Santa Barbara

UCSD: University of California-San Diego

ULSI: ultralarge-scale integration

UV: ultraviolet

YBCO: $\mathrm{YBa}_{2} \mathrm{Cu}_{3} \mathrm{O}_{7}$ 
cations, now starts to play a role in obtaining new oxide materials.

P.A. Salvador (CMU) reported on the epitaxial stabilization of hexagonal manganites on the $\mathrm{MgO}(111)$ and $\mathrm{Pt}(111)$ surfaces. The structural coherence at the filmsubstrate interface is responsible for the stabilization. Kaul's presentation showed that this phenomenon can be used for selective epitaxy of various heterostructures. The example of the realized grating $\left(\mathrm{NdNiO}_{3} / \mathrm{La}_{0.7} \mathrm{Ca}_{0.3} \mathrm{MnO}_{3}\right)_{n}$ confirms that epitaxial stabilization in now not only a way to explain the appearance of unexpected phases, but a promising approach for new materials synthesis.

The importance of thermal-barrier coatings (TBCs) is continuously growing with increased demands on gas-turbine performance both for land-based power generation and for jet engines, and more and more for large internal-combustion engines. These trends were highlighted by A.R. Nicoll (Sulzer Metco) in Symposium $\mathrm{HH}$. In particular, the need for higher performance coating materials was emphasized, showing better thermal stability than the most widely used zirconia partially stabilized by yttria.

E.R. Fuller (NIST) reported on the use of object-oriented finite element analysis for the development of numerical predictions of thermal and mechanical properties of coatings with specific microstructures. J. Ruud (GE) described how different microstructures can change thermal conductivities by a factor of four, and life in furnace cycling tests by a factor of two. T.A. Dobbins (Penn State, NIST) explained the difference in sintering behavior for different microstructures, in which nanopores are more likely to close than larger pores due to sintering upon heating.

\section{Nanotechnology}

In the area of nanomaterials, H.G. Craighead (Cornell) demonstrated, in Symposium H, how functional nanostructures can be created by still relying on top-down fabrication. Objects of $30 \mathrm{~nm}$ in size (close to the size of nanotubes) can be made in such a way that they can be controllably placed. In particular, Craighead showed how DNA molecules can be

\section{Materials at the Undergraduate Level Emphasized in Education Symposium}

This year's MRS Symposium on materials science education (JJ) focused on the undergraduate curriculum in MSE. Some speakers discussed their programs to introduce materials to undergraduate science and engineering students, while others provided examples of how they teach materials concepts to the MSE majors. Another concern expressed is how students are prepared for industry upon graduation.

A.J. Moll (Boise State) provided information on why an industrial emphasis should be implemented in the undergraduate MSE curriculum. Based on federal studies in the United States, Moll assessed that among undergraduate MSE students, $\sim 50 \%$ who finish with a BS degree obtain jobs in their field, and $\sim 40 \%$ find a job closely related to their field of study. Students who pursue an advanced degree typically do so in another area such as law or business administration. More than $60 \%$ of engineers have a BS as their highest degree. As these engineers work in industry, Moll suggests that they should receive a general engineering degree in undergraduate school, saving specialization for advanced degrees. The undergraduate students should also be exposed to processing and manufacturing, she said. Furthermore, the criterion of success of the department is the ability of undergraduate students to get their first job.

K.J. Duxstad (Seagate Technology) delineated the type of skills students need to acquire for industry projects. In particular, researchers need to be able to design new projects by identifying customer requirements and technological and logistical gaps. They need to know how to communicate to different types of audiences about their experimental results, recommendations, timelines, and required resources to complete the projects. Statistical analysis of laboratory data plays a significant role in industry work, she said.

Following G.C. Farrington's (Lehigh) plenary address, which included the importance of attracting and retaining undergraduate students in the MSE department, several speakers discussed progress in this area. W. Jones Jr. (SUNY-Binghamton) described a one-course seminar directed toward science and engineering majors who have yet to determine their specific career goals. The course is an introduction to chemistry that implements materials. The curriculum was developed to teach the relevance of chemistry to students' interests by focusing on active areas that are, by nature, interdisciplinary. This course has increased student enrollment as it drew in engineering students (requirement course) and non-U.S. students. Jones described the integrated lecture and on-line experience. In-class lectures are held once a week, typically involving a guest speaker from industry, for example, along with on-line lectures, assignments, and discussions. This setup has also drawn in students from industry who are otherwise unable to attend classes; they performed at the top third of the class.

V. Goldberg of Simmons College for undergraduate women described a collaboration with Cornell University that introduces physics and chemistry students to opportunities in materials research. The topic chosen for this project is the degradation processes in organic LEDs because it involves various experimental techniques for which sophisticated instrumentation is provided by Cornell.

D. Bahr (Washington State) described an introduction to materials course for nonengineering majors designed to demonstrate, for the general public, why materials are important. The course includes videos and general articles from publications such as Scientific American. The students tend to like having a variety of topics covered, Bahr said.

J. Isaacs (Northeastern Univ.) talked about managing group projects for an introduction to materials course. With a class size of 50-70 students, Isaacs breaks the class into groups of 3-4 students who explore materials used in common objects. The groups are self-regulated, which influences each student to participate, and studies on collaborative learning show that students learn more and retain the information longer than through traditional class settings.

W. Crone, director of Education and Outreach for the University of Wisconsin, Madison MRSEC, lured "audience participation" in the symposium with demo kits used in undergraduate education that utilizes the topic of nanotechnology to teach concepts in MSE. In one demo, a refrigerator magnet was used to simulate the atomic force microscope, and in another, an Optical Transform Kit was used to demonstrate diffraction patterns.

D. Srolovitz (Princeton) described a computer module developed to go with a physical chemistry of materials textbook. His project provides a computer laboratory through which undergraduate students experience decision-making processes for experiments. The computer laboratory is not meant to replace a real laboratory experience, but it supplements textbook learning and provides an opportunity to develop the level of expertise seldom realizable in laboratory courses. 
threaded through a regular system of nanofluidic channels in response to an electric field. By sending an array of such molecules of different lengths down into these channels, it is possible to identify types of molecules by the "on and off" configuration based on whether the molecules make it all the way into the channel in a given time.

In Symposium J, J.L. Gole (Georgia Tech) described a method for metallizing the surface of porous silicon to create extremely low-resistance contacts. Photoluminescence-induced metallization uses light emission from porous Si. The technique involves an electroless solution in contact with a porous Si surface that contains a metal ion that can be reduced. If there is no photoluminescence, there is no metallization. In this process, nanoparticles of titanium dioxide are placed in the microporous $\mathrm{Si}$ array and excited by using the photoluminescence or electroluminescence from the porous Si. Initially there was a problem, however, since both the photo- and the electroluminescence from the porous Si $(500-650 \mathrm{~nm})$ are below the energy needed for the excitation of $\mathrm{TiO}_{2}$. Gole's research team overcame this problem by developing a method for directly nitriding nano- $\mathrm{TiO}_{2}$ using triethylamine, thereby sufficiently lowering its excitation energy. The reaction occurs in seconds, producing a powder consisting of nanostructured agglomerates of $\mathrm{TiO}_{2}$. Gole said they believe this is an example of the use of the nanophase to increase technological efficiency. This process did not work when the researchers tried to treat either the rutile or anatase forms of $\mathrm{TiO}_{2}$ in a similar manner.

Symposium G opened with recent advances in electron optics. S.J. Pennycook (ORNL) described how aberration-corrected STEM extends the resolution of electron optics to unprecedented scales. Subsequent talks included a discussion of chemical mapping using spectroscopic electron tomography, the use of aloof-transmission EELS, and several examples of applications of high-resolution electron imaging in nanostructured and nanocomposite materials. The poster sessions featured a wide range of presentations on the development and use of nanoscale characterization tools. The posters covered measurement of mechanical properties on the nanoscale level, recent developments in scanning probe methods, and applications of cathodoluminescence. Overall, the symposium presented a wide-ranging overview of the use of modern characterization tools for the study of nanometer-length scale phenomena in complex materials, and of technical advances in the develop-

\section{Poster Prizes Awarded at the 2002 MRS Fall Meeting}

The 2002 MRS Fall Meeting chairs awarded prizes for the best poster presentation. Prize recipients from poster sessions received $\$ 500$, a certificate, and the honor of having the winning poster displayed for the remainder of the Meeting. Posters awarded prizes and their authors were (B9.22) Interfaces between Metal Electrodes and Photo-Active

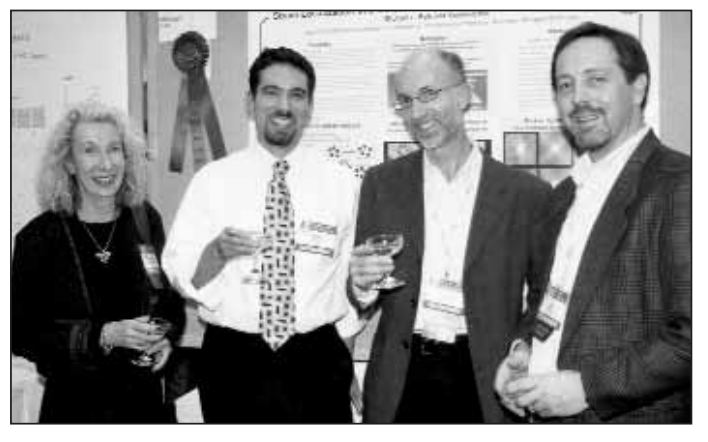

Polymers Studied by Photoelectron Spectroscopy, Y.J. Bhandari, K. Demirkan, Z.I. Niazimbetova, A. Menon, S. Vaidynathan, M.E. Galvin, and R.L. Opila (Univ. of Delaware); (B9.37) Nickel-Plated Polymer/Colloid Microarrays via Polymer-on-Polymer Stamping, H. Zheng, M.F. Rubner, and P.T. Hammond (MIT); (G7.42) Synthesis and Characterization of $\left.\mathrm{Si}_{1-x}\right) \mathrm{Ge}_{x}$ Nanowires, K.W. Adu, R. Gupta, G.U. Sumanesakera, B.K. Pradhan, and P.C. Eklund (Penn State); (G13.11) Atomic and Electronic Structures of Nano-Interface in Au/TiO Catalyst-Electron Microscopic Approach, S. Ichikawa, K. Okazaki, T. Akita, M. Okumura, K. Tanaka, and M. Kohyama (AIST-Kansai, Osaka, Japan); (H7.15) Nanostructured Materials on Carbon Nanowall Templates, Y. Wu and B. Yang (Natl. Univ. of Singapore); (K5.2) Confinement of Screw Dislocations to Predetermined Lateral Positions in (0001) 4H-SiC Epilayers Using Homoeptiaxial Web Growth, P.G. Neudeck, J.A. Powell, G.M. Beheim, and E.L. Benevage (NASA Glenn Research Center) and A.J. Trunek and D.J. Spry (OAI, Cleveland, OH); (L3.18) Dislocation Reduction in Heteroepitaxial Nonpolar (112̄0) a-Plane GaN Films via Lateral Overgrowth, M.D. Craven, S.-H. Lim, F. Wu, J.S. Speck, and S.P. DenBaars (UCSB); (L6.17) Multicolor Integration on Rare-Earth-Doped GaN Electroluminescent Thin Films, Y.Q. Wang and A.J. Steckl (Univ. of Cincinnnati); (L11.24) Composition Dependence of the Fundamental Bandgaps of Group III-Nitride Alloys, J. Wu, W. Walukiewicz, K.M. Yu, J.W. Ager III, and E.E. Haller (UC-Berkeley) and H. Lu and W.J. Schaff (Cornell); (M8.12) Scattering and Dephasing in Semiconductor Heterostructures, R. Ascázubi, O.C. Akin, T. Zaman, and R. Kersting (RPI) and G. Strasser (TU Wien, Austria); (U4.2) Investigations into Mesoscopic Ferroelectric Structures Prepared by Nanoimprint Lithography, C. Harnagea, M. Alexe, D. Hesse, and U. Gösele (MPI, Halle, Germany); (Z3.32) Using Strain to Dynamically Tune the Properties of $\mathrm{La}_{0.5} \mathrm{Sr}_{0.5} \mathrm{MnO}_{3}$ on $\mathrm{BaTiO}_{3}$, D. Dale, A. Fleet, J.D. Brock, and Y. Suzuki (Cornell); (BB5.14) Nanoporous Behavior Induced by Excess Vacancy Clustering in Rapidly Solidified B2 FeAl Ribbons, T. Haraguchi, K. Yoshimi, H. Kato, S. Hanada, and A. Inoue (Tohoku Univ., Japan); and (CC6.20) Simulations of the Failure Modes of Model Metallic Glasses, F. Albano, B. Hu, and M.L. Falk (Univ. of Michigan) and A. Paranjpye and G. Beltz (UCSB).

ment of new spatially resolved characterization methods, which enable a new understanding of fundamental phenomena at the nanoscale level.

\section{Soft Materials}

Innovations in soft materials were discussed in one of the clusters of symposia. D.C. Martin (Univ. of Michigan) described in Symposium B how "fuzzy" conducting polymer coatings can be fabricated to improve the function of neural prosthetic devices, which, when implanted in the brain, restore some measure of vision or hearing. The fuzzy interfaces are designed to mediate the difference in elastic modulus of a stiff (e.g., silicon) probe (of $~ 150$
GPa) interfacing brain tissue (with elastic modulus of a few $\mathrm{kPa}$ ). Martin showed how electrochemically deposited polymers can be tailored to form the porous interfaces, reducing the stiffness while allowing material and electrical signals to pass through. Hydrogels, polymers that are $95 \%$ water, could be used as the interface with the probe. They are inserted into the brain in a dehydrated form to give mechanical rigidity, then rehydrated once in place to provide the better-matched mechanical properties.

In a talk on high-performing semiconductor polymer designs for FETs, in Symposium D, B. Ong (Xerox Research Centre of Canada, Mississauga, Canada) 
described polythiophene with electronic properties an order of magnitude greater than those of current polymeric materials, which could hasten the development of printed polymer transistors. This development could be applied in a rollto-roll manufacturing process, which is currently used for publishing and for manufacturing solar cells, to create flexible printed circuits.

In a session on power suppliers for electronics on nonconventional substrates, within the same symposium, J. McDermott (Infinite Power Solutions) presented work on a thin-film solid-state lithium battery for electronics worn on the body. His group is developing these batteries with an almost infinite lifetime for lowpower circuits, which are based on an electrolyte (nitrogen-doped ortho lithium phosphate) developed at Oak Ridge National Laboratory. The most significant component of these batteries is their ambient energy recharge system that immediately tops off the battery's energy to fill its capacity. In effect, the entire package becomes an autonomous energy power pack. As the size of electronic components becomes increasingly reduced, it is anticipated that they will be combined with these thin-film batteries that are constantly recharged wherever they are located.

\section{Electronic Properties}

More research was unveiled on electronic properties that led, a few years ago, to the discovery of $\mathrm{MgB}_{2}$ as a superconductor and that recently opened the field of spintronics. The first talk in Symposium $\mathrm{S}$ was given by J. Akimitsu (AoyamaGakuin Univ., Japan) whose group discovered superconductivity in $\mathrm{MgB}_{2}$ in 2001. In discussing the superconducting properties of $\mathrm{MgB}_{2}$ in relation to its structure, Akimitsu compared $\mathrm{MgB}_{2}$ and $\mathrm{NbB}_{2}$, which have similar structures but very different properties. He mentioned new superconducting materials $\operatorname{Re}_{3} \mathrm{~B}, \operatorname{Re}_{7} \mathrm{~B}_{3}$, and $\mathrm{W}_{7} \operatorname{Re}_{13} \mathrm{~B}$, which, unfortunately, have a low superconducting temperature. Turning to applications, Akimitsu said that the addition of nano- $\mathrm{SiO}_{2}$ made it possible to manufacture tapes. A research group at Hitachi has been able to make $\mathrm{MgB}_{2}$ superconducting wire but the $T_{\mathrm{C}}$ is still low. Akimitsu's presentation was followed by the $\mathrm{MgB}_{2}$ group at Ames Laboratory regarding its work on synthesis and basic properties of the material.

In Symposium Q, developments in molecular nanomagnetic materials were presented. D.N. Hendrickson (UCSD) discussed synthetic methods to "engineer" single-molecule magnets (SMMs), including their total spin, magnetic anisotropy, intermolecular exchange interactions, and molecular environments. In particular, he showed examples of Mn-based half-integer spin systems, spin-parity effects in these systems, exchange coupled $\mathrm{Mn}_{4}$ and 3D exchange coupled $\mathrm{Ni}_{4} \mathrm{SMMs}$.

S. Hill (Univ. of Florida) discussed the power of high-frequency EPR spectroscopy to understand basic interactions in SMM, including dipolar interactions, intermolecular exchange, and modulations in the local molecular environments affecting magnetic anisotropy. A.D. Kent (NYU) showed how subtle changes in solvent positions affect magnetic quantum tunneling and how SMM crystals can be magnetically "distilled" to reveal the fundamental molecule symmetries important to quantum tunneling.

As magnetic storage and memory technologies advance, interest increases in the fundamental mechanisms and dynamics of magnetization switching, as was addressed in a session on spin dynamics in Symposium R. The spatial distribution of distinct magnetic excitations in patterned structures is one area of active interest (B. Hillebrands, Univ. of Kaiserslautern, Germany; M. Freeman, Univ. of Alberta, Canada). Damping mechanisms of magnetic excitations can be either intrinsic to specific magnetic features (T.J. Silva, NIST) or dependent on magnetic proximity

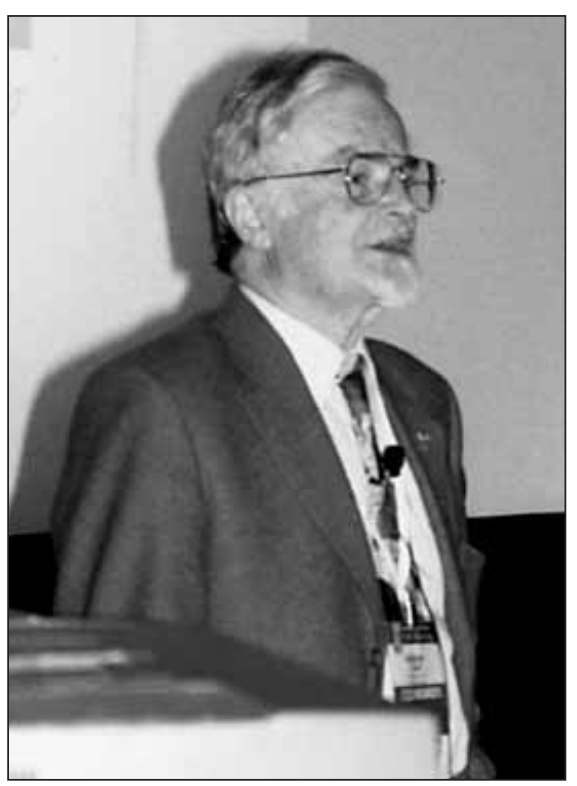

Robert W. Cahn (University of Cambridge, UK), recipient of the MRS 2002 David Turnbull Lectureship, presented his talk on "Metallurgists and Materials

Scientists: Scope for Skepticism?" effects (B. Heinrich, Simon Fraser Univ., Canada). Current-induced magnetic excitations (W.H. Rippard, NIST) remain of great interest, especially as they relate to spintronic devices.

For further details on the technical content of the Meeting, see the following symposium summaries. Proceedings are available on-line at www.mrs.org.

\section{Defects Manipulated to Control \\ Polymer Properties}

(See MRS Proceedings Volume 734)

In Symposium A on Defect-Mediated Phenomena in Ordered Polymers, D.C. Martin (Univ. of Michigan) discussed defects in electronically conductive polymer materials [e.g., pentacene, poly(diacetylene)], focusing in particular on the growth of single-domain crystals and their influence on electronic properties and induced deformations. There was strong interest in topological defects in block copolymer systems as well, both their role in graingrowth kinetics and thermodynamics. N.P. Balsara (UC-Berkeley) described composition fluctuations in block copolymer melts near the order-disorder temperature as measured by light scattering and confirmed by electron microscopy. R.A. Register (Princeton) and E.J. Kramer (UCSB) discussed the role of topological defects in the melting of thin films of block copolymer microdomains. The pressing fundamental question appears to be whether the melting is consistent with the KTHNY theory of defect-mediated melting. Control over microdomain positioning was pursued as well, both by using mica facets (step edges) and by microfabricated channels (the latter by E.L. Thomas and C.A. Ross, both of MIT). Good alignment was demonstrated and these microdomains were subsequently transformed into metallic dots for information storage.

The role of defects during shear was explored by several researchers, including D. Morse (Univ. of Minnesota), K.I. Winey (Univ. of Pennsylvania), and I. Hamley (Univ. of Leeds). Simulations show that shear can remove or produce defects, depending upon the parameters applied. Extensive examination of these structures, and the resulting structures (e.g., $\mathrm{T}$ junctions and kink boundaries) that can form in lamellar-like systems, were discussed by M. Schick (Univ. of Washington) and R. Kamien (Univ. of Pennsylvania). R. Weidisch (IPF) discussed the influence of such defects and copolymer architecture on material properties such as toughness and flow behavior. Several aspects of crystallization were explored, from the origin of chirality in spherulites (M. Muthukumar, Univ. of Massachusetts) 
to the influence of nucleating agents (G. Matsuba and M.L. Walker, both of NIST) to wear-resistance of crystallized polyethylene in orthopedic biomaterials (A. Bellare, Harvard).

\section{Polymer-Metal Interface Applications Range from Electronic Devices to Biomaterials}

(See MRS Proceedings Volume 734)

Various communities that work on polymer-metal interfaces came together for Symposium B. The tutorial given on Sunday by S.P. Anastasiadis (Univ. of Crete, Greece) and W.R. Salaneck (Linköping Univ., Sweden) established the connection between the structure of interfaces and their electronic properties. The most well-attended sessions were those on interface energetics and on interfaces in electronic devices, reflecting the recent interest in using conjugated polymers for applications such as light-emitting diodes, transistors, and photovoltaics. Interfaces between metals and biopolymers were also addressed in two separate sessions, which attracted a diverse audience.

Symposium Support: ARO.

\section{Biomolecules Utilized as Key} Nanoscale Building Block for New Materials and Functional Devices (See MRS Proceedings Volume 735)

Symposium C, Bio-Inspired Nanoscale Hybrid Systems, provided an extensive overview of the new and advanced approach to synthesize functional materials and to fabricate nanoscale devices using biomolecules as a key building block. Nature uses molecular recognition between complex biomacromolecules to form sophisticated meso- and macroscopic architectures with control over the placement and orientation of nanoscopic building blocks. On the other hand, the advances of nanotechnology provide new nanoscale structures, including nanoparticles, nanowires, and nanofabricated circuits. The marriage between biomolecules and these new nanostructures constituted the basis for significant scientific developments and applications presented in the symposium.

For example, specific interactions between biomolecules can be used as a major driving force to build sophisticated 1D, 2D, and 3D architectures. C.A. Mirkin (Northwestern Univ.) described a process whereby biomolecular interactions such as DNA hybridization can direct the assembly of nanoparticles to form desired architectures. Several researchers reported various bio-inspired synthesis and assembly results such as the synthesis of metallic nanowires from

\section{Graduate Students Receive Gold and Silver Awards}

During an awards ceremony held on December 4 at the 2002 Materials Research Society Fall Meeting, graduate student finalists received Gold and Silver Awards.

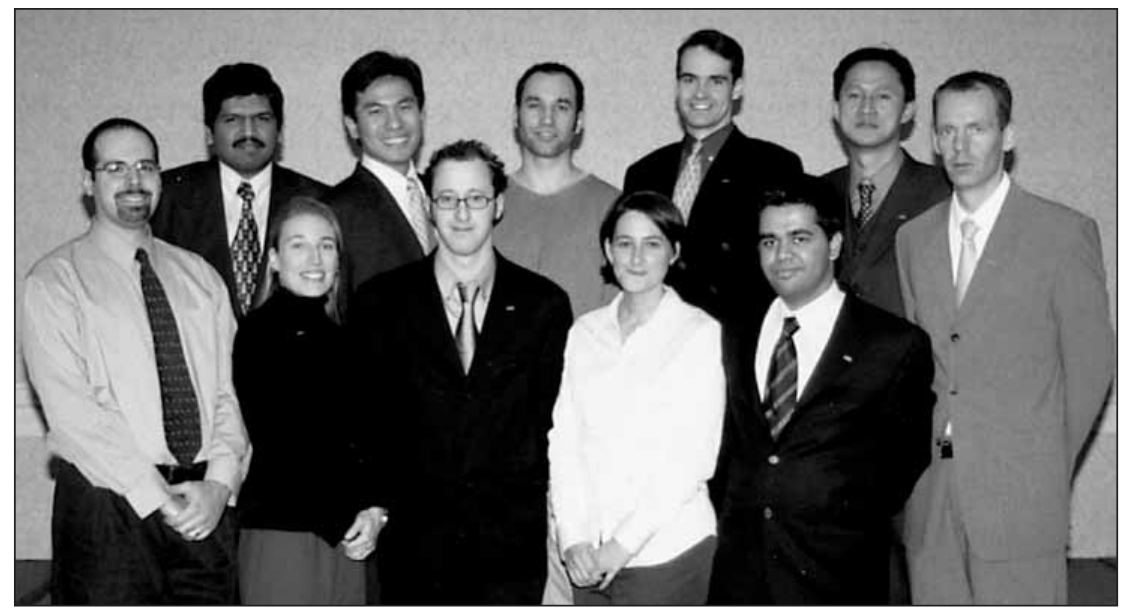

Gold Graduate Student Awards went to (first row, left to right): Gianni Taraschi (Massachusetts Institute of Technology), Krystyn J. Van Vliet (Massachusetts Institute of Technology), Mathew M. Maye (State University of New York, Binghamton), Jodie E. Bradby (Australian National University, Australia), Sarbajit Banerjee (State University of New York, Stony Brook), and Rainer J. Hebert (University of Wisconsin, Madison); (second row, left to right): Rahul Panat (University of Illinois, Urbana-Champaign), Yu-Ming Lin (Massachusetts Institute of Technology), James P. Buban (University of Illinois, Chicago), Eric N. Brown (University of Illinois, Urbana-Champaign), and Seung-Wuk Lee (University of Texas, Austin).

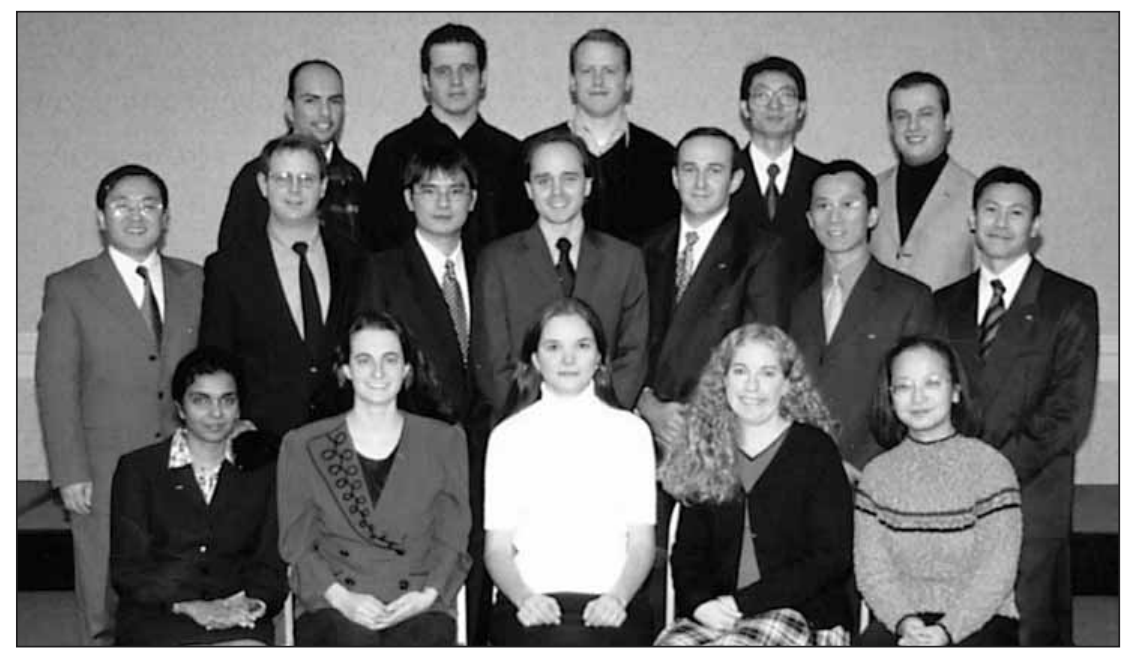

Silver Graduate Student Awards went to (first row, left to right): Anupama Mallikarjunan (Rensselaer Polytechnic Institute), Marcie R. Black (Massachusetts Institute of Technology), Albina Y. Borisevich (University of Pennsylvania), Jennifer L. Gray (University of Virginia), and Yu Lu (University of Washington); (second row, left to right): Guangwen Zhou (University of Pittsburgh), Erik L. Waldron (Boston University), Wangyang Ni (Michigan State University), Dean M. DeLongchamp (Massachusetts Institute of Technology), Maxim B. Kelman (Stanford University), Kai-Chieh Chang (Carnegie Mellon University), and Ariya Akthakul (Massachusetts Institute of Technology); (third row, left to right): Ricardo Ruiz (Vanderbilt University), Marko Loncar (California Institute of Technology), Zachary Donhauser (The Pennsylvania State University), Yinmin Wang (Johns Hopkins University), and Ahmet S. Ozcan (Boston University). Not shown is Yulia S. Petronyuk (Institute of Biochemical Physics-RAS, Russia). 
peptides, DNA-mediated assembly of carbon nanotubes, and 3D assembly of nanoparticles using a virus as a template.

New advanced characterization tools are being applied for the quick and high precision analysis of bio-inspired hybrid nanostructures. H. Fuchs (Univ. of
Münster, Germany) presented "advanced dynamic scanning probes for the characterization of self-organized organic layers." Several researchers studied electron transport properties of hybrid nanostructures by scanning probe techniques, using a conducting tip of an atomic force

\section{Microelectronics Opens New Frontier (See MRS Proceedings Volume 736)}

For many years, the progress in microelectronics has been associated with reducing the minimum feature size of integrated circuits. This trend described by Moore's law is rapidly reaching the point of diminishing returns as the minimum feature size approaches dimensions comparable to atomic sizes. A new frontier of microelectronics might involve moving away from conventional silicon chips into new materials that allow cheap manufacturing processes for microelectronic and nanoelectronic devices and circuits on nonconventional, flexible, giant-area substrates (see Figure 1). Dimensions of these new electronic circuits will be comparable or even as large as a human body. Giant-area electronics on flexible substrates will enable numerous applications from electrotextiles to flexible displays, from thin-film batteries to novel photovoltaic devices, and from sensitive skin for robotics and medical applications to antiterrorist systems and smart buildings. Therefore, Symposium D, entitled Electronics on Nonconventional Substrates-Electrotextiles and Giant-Area Flexible Circuits, caused a great deal of interest.

In the first session, E. Ethridge (DARPA) gave an overview of electrotextiles, which her agency pursues for its focus on military applications. The researchers are addressing how to incorporate very small sensors in very large areas. They would like to add an electronic capability to the existing infrastructure by integrating the devices within the structure.

J.F. Muth (NCSU) discussed signal propagation in electrotextile circuits, where dimensions are measured on the scale of yards instead of inches. M. Orth (Intl. Fashion Machines, Cambridge, Mass.) discussed color changing and touch-sensing flexible-textile circuitry, and D. Cadogan (ILC Dover, Frederica, Del.) considered manufacturing aspects of electrotextile technology. Textile networks for wearable electronics technology were reviewed by P. Wilson (Foster-Miller, Waltham, Mass.). Electrotextiles emerged as one focus of the symposium, with details discussed ranging from washing electrotextiles (M. Agpaoa-Kraus, Foster-Miller, Waltham, Mass.) to mechanical testing (J. Slade, Foster-Miller, Waltham, Mass.).

Two other key areas dealt with electronics and photonics on flexible substrates. S. Wagner (Princeton) discussed electronic components for a conformal and drapeable surface. Flexible polyimide sensitive skin electronics was considered by J. Engel (Univ. of Illinois). Xerox (B. Ong) and Korea Electronics Technology Institute (S.K. Park) groups reported on high-performance polymer FETs.

The highlights of the symposium were reports on low-voltage organic thin-film transistors on flexible plastic substrates with anodized $\mathrm{Ta}_{2} \mathrm{O}_{5}$ gate insulators used for driving organic electroluminescent devices (Y. Inoue, Science and Technical Research Laboratories of NHK, Tokyo) and on paperlike organic electroluminescent displays (Y. Ohmori, Osaka Univ., Japan). B.J. Neudecker (ITN Energy Systems, Littleton, Colo.) described the development of thin-film solid-state batteries on fiber substrates.

Nonlithographic, stamping, and printing technologies for electronic devices were discussed in a separate session. microscope, or by electrode junctions. On the other hand, conventional fluorescence microscopes, scanning electron microscopes, and transmission electron microscopes are optimized for studying hybrid nanostructures.

Bio-inspired hybrid nanostructures have resulted in new commercial applications. P. Alivisatos (UC-Berkeley) applied functionalized nanocrystals for biological applications, including ultrasensitive biomolecular detection schemes. $\mathrm{M}$. Zheng (DuPont) presented bioassembly of nanomaterials for nanoelectronics where bio-inspired hybrid nanostructures act as electronic components. Functionalization of solid surfaces with biomolecules is also becoming increasingly important because of possible bioengineering applications such as creating biocompatible solid surfaces, promoting cell adhesion and growth on solid surfaces, and developing an artificial bone-graft substitute.

Symposium Support: AFOSR; AlCove Surfaces GmbH; Henkel KGaA, Germany; NIST; and Pfizer Global RED.

\section{Exploration of Semiconductor Quantum Dots Serves Advancement of Nanotechnology \\ (See MRS Proceedings Volume 737)}

Semiconductor quantum dots are one of the most important areas of exploration in nanotechnology and nanoscience. The study of quantum dots focuses on the properties of semiconductor particles when they are $\sim 1 \mathrm{~nm}$ in size. New physical behavior and potential applications have been pursued in these materials over the last few decades. In Symposium E on Physics and Technology of Semiconductor Quantum Dots, two main fabrication approaches were presented: gas-phase deposition, which produces Stranski-Krastanov quantum dots, and colloidal chemistry, which produces nanocrystals. Highlights included advances in the traditional optoelectronic applications of these materials as well as newer uses, such as fluorescent tags in living biological organisms.

Room-temperature stimulated emission from ensembles of spherical (V. Klimov, LANL) and rod-shaped (U. Banin, Hebrew Univ.) nanocrystals was demonstrated, implying a new class of widely tunable lasers. Efficient Förster energy transfer in nanocrystals was shown to enable excitation of $\mathrm{Er}^{3+}$ (M. Zacharias, MPI) and may allow more efficient light harvesting in optical devices (J. Hollingsworth, LANL). The coherent optical properties of single semiconductor quantum dots were discussed. The truth table of a classical controlled NOT gate operation was shown 


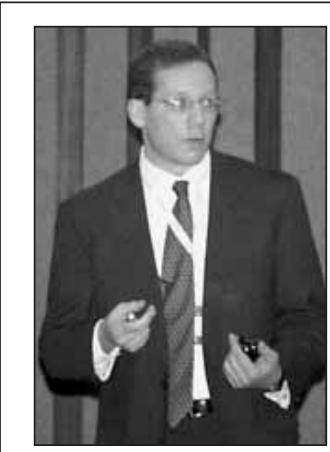

Charles Lieber, MRS Medalist
Silicon and Other Semiconductor Nanostructures Wired for Success (See MRS Proceedings Volume 737)

Symposium F, Nanocrystalline Semiconductor Materials and Devices, revealed the latest research concerning the synthesis and characterization of silicon microstructures and their device applications. The high point of the symposium was the MRS Medal Award presentation by Charles Lieber from Harvard, who discussed his groundbreaking semiconductor nanowire research. From new computing platforms to sensor design, these nanoscale inorganic structures stand poised for a broad range of critical fundamental studies and applied technologies.

Complementing this work were 19 presentations outlining a range of exciting and novel semiconductor nanowire studies, including preparation, utilization for RAM devices and nanocontacts, heterostructure device synthesis, studies of optical and lasing properties, and others. Research from HewlettPackard, Motorola, Intel, Matsushita, and others concerning application and commercialization of Si nanocrystals and related nanostructures for memory and light-emitting applications permitted insight into the process of commercialization of what were once strictly laboratory denizens.

Other work presented early in the symposium demonstrated that soft structures such as biological molecules and organic monolayers can be interfaced with silicon, germanium, and diamond nanostructured materials for possible in vivo chipbased implants. Important for actual device manufacture, these soft structures, as well as nanoparticles based on different materials such as noble metals, can be patterned laterally on both the micro- and nanoscale levels. For instance, work from IBM revealed that ion beams can be utilized to pattern microstructures in the low nanometer regime.

Symposium Support: Motorola and Texas AEM Univ. using nonlinear coherent optical spectroscopy on a single quantum dot (X. Li, Univ. of Michigan), which is an important step toward a solid-state-based quantum computer. Also, optical Rabi oscillations have been measured in the photocurrent of a single quantum-dot photodiode (A. Zrenner, Paderborn).

One of the most exciting presentations of the symposium was on the use of water-soluble nanocrystals as an in vivo fluorescence probe for cell lineage tracing (B. Dubertret, Rockefeller Univ.). By encapsulating nanocrystals in a micelle, extremely stable fluorescent tags were obtained and used in vivo. The nanocrystals were injected into a frog embryo and used to trace the development of the organism as it grew into a tadpole.

Symposium Support: Evident Technologies, IBM T.J. Watson Research Ctr., and LANL.

\section{Molecular Electronics, Nanoscale Biological Systems Probed through Nanoscale Characterization (See MRS Proceedings Volume 738)}

Advances in probing structure and properties at atomic, molecular, and nanoscale resolution were the focus of Symposium G on Spatially Resolved Characterization of Local Phenomena in Materials and Nanostructures. Topics ranged from recent developments in electron microscopy, scanning probe microscopies, optical microscopy and spectroscopy, molecular electronics, nanoscale biological systems, and studies of selfassembled monolayers.

Several sessions focused on different aspects of spatially resolved optical characterization tools, including the use of near-field cathodoluminescence to obtain nanometer-scale information (L.J. Balk,
Univ. of Wuppertal, Germany), spatially resolved luminescence (S. Ostapenko, Univ. of South Florida), and Raman spectroscopies in semiconductors and device structures (D.D. Tuschel, ChemIcon, Pittsburgh, Pa.); recent developments in immersion lens microscopy (M.S. Ünlü, Boston Univ.); and the use of near-field optical microscopy for the nanoscale study of organic electronic materials (P. Barbara, Univ. of Texas, Austin). Other presentations explored new applications of these tools in both semiconductor and soft material characterization, applications of spatially resolved Raman spectroscopy in a variety of materials, and applications of near-field optical spectroscopy for nanostructure characterization.

Nanoscale characterization is making some of the largest strides in the area of biological/physiological science, including the use of fluorescent semiconductor nanocrystal probes to optically image cell surface receptors (S.J. Rosenthal, Vanderbilt Univ.), and the use of atomic force microscopy and single-molecular force measurements to study nanofibers of spider dragline silk (H. Hansma, UCSB).

Advances in measuring transport in individual nanotubes and molecular devices were presented in the session on molecular electronics. A.T. Johnson (Univ. of Pennsylvania) demonstrated imaging of individual defect electronic structures in carbon nanotubes, while P.S. Weiss (Penn State) explored single-molecule switching behavior. The behavior of ordered assemblies of electronically active molecules was examined with new probes that access frequency-dependent properties with the potential to elucidate fundamental transport mechanisms. The role of quantum confinement on the vibrational properties of semiconductor nanowires and size-dependent properties of particles was addressed.

Four related sessions explored the use of scanning probe techniques for nanoscale material characterization. The development of high spatial and high temporal resolution probes through the use of ultrafast gated scanning tunneling methods was described by A.J. Taylor (LANL). The use of STM to probe potential distributions in semiconductors was the focus of R.M. Feenstra's (CMU) presentation, and approaches for measuring single-molecular electrodynamic fields were described by S. Eppell (CWRU). Additional presentations covered magnetic resonance force microscopy and scanning-probe-based methods for mechanical-property measurements.

Symposium Support: ARO.

\section{The Nanoscale World Is Flat, but Changing}

(See MRS Proceedings Volume 739)

The Three-Dimensional Nanoengineered Assemblies symposium (H) brought together researchers worldwide who are trying to control matter on the nanometer scale. The physics, chemistry, and materials properties of matter at this level present new opportunities but also new challenges, particularly in the area of fabrication. The "flatland" approach to materials processing, handling, and behavior is simply less appropriate as the $x, y$, and $z$ length scales become similar. The presentations provided a snapshot of the research being done to understand how to make and use 3D structures on the nanoscale. Presentations by U. Goesele (MPI, Halle, Germany), S.R.J. Brueck (Univ. of New Mexico), H.G. Craighead 
(Cornell), and others pushed standard silicon techniques to achieve something new. Many other talks presented work involving nonsilicon materials.

In general, the true nanoscale work is not fully 3D. Because of this, many novel approaches to materials processing and applications for $>2 \mathrm{D}$ structures were included in the symposium. These talks were important because they advance present practice, even if they cannot yet be applied to the nanometer scale.

Talks ranged from soft lithography to biomimetics and from electrochemistry through ion-beam processing techniques. One session included talks by M.A. El-Sayed (Georgia Tech), F. Träger (Univ. Kassel, Germany), and H.A. Atwater (Caltech) that highlighted an emerging area of research associated with plasmon processes on the nanoscale level. Research was described on nanotubes, nanosprings, and nanowires by W.A. de Heer (Georgia Tech), R. Penner (UC-Irvine), D.N. McIlroy (Univ. of Idaho), and others. Talks presented 3D structures made using ion- and electron-beam-mediated CVD. Another theme that ran through the symposium can be found in the work that is pushing embedded 3D processing techniques that modify a material with less traditional methods. Three-dimensional direct-write processing using end-of-range ion-beam methods and two-photon processing of polymers and glasses were presented. Another group of talks presented a more biological approach to the fabrication of 3D nanostructures.

Symposium Support: AFOSR, ARO, NSF, and ONR

\section{Fundamental Science and Structural Applications Covered in Area of Nanomaterials}

\section{(See MRS Proceedings Volume 740)}

Symposium I on Nanomaterials for Structural Applications provided an overview of current multidisciplinary research in this rapidly growing field with the primary focus of reinforcing the relationship between basic science and engineering at the nanoscale level. Thematic sessions covered nanostructured bulk materials, films, coatings, and nanocomposites. These new materials are now being introduced in structural applications, such as wear resistance and plastic-forming, and load-bearing uses. Nanophase or nanocrystalline materials are also being used in electronics, refractory, biological, and catalytic applications. Progress in a wide range of structural applications for nanomaterials crucially depends on the development of new fabrication and processing technologies, along with a funda-

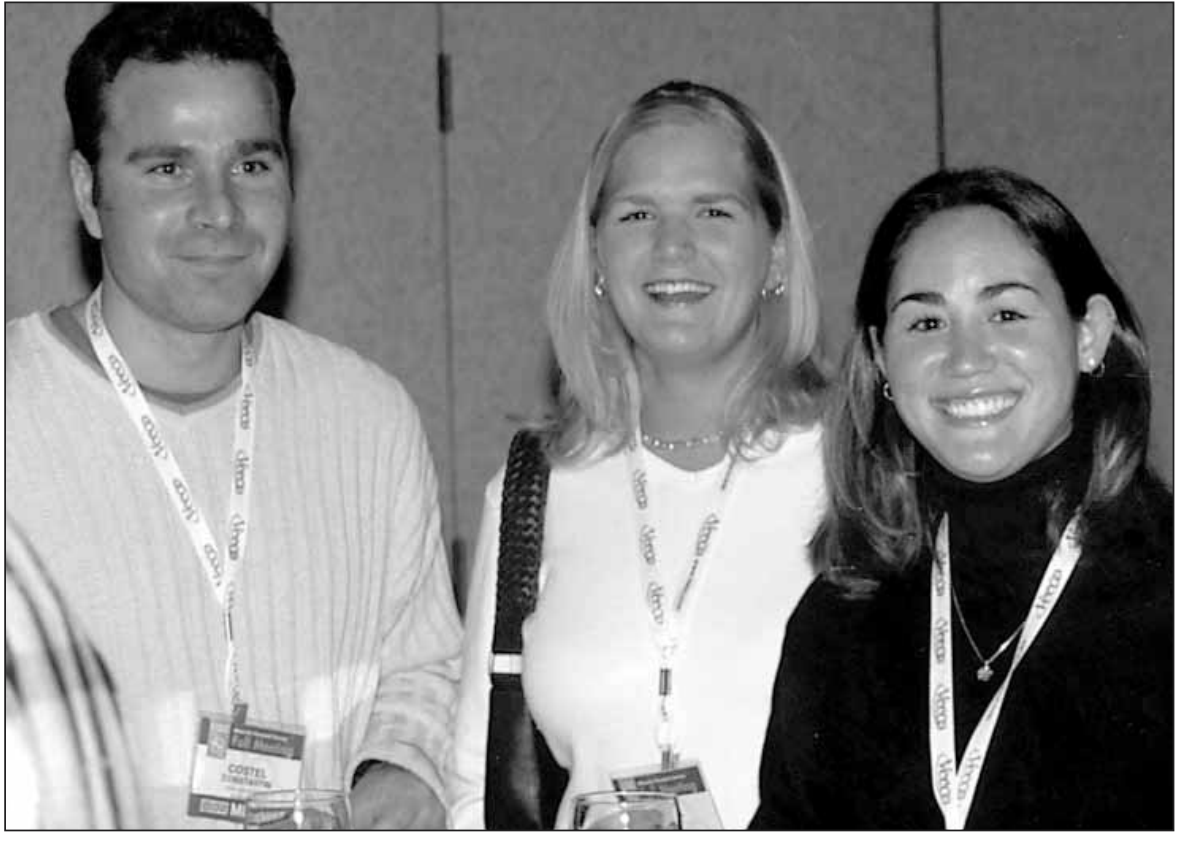

A student mixer was held Monday evening to allow student attendees to meet in an informal setting.

mental understanding of the relationship between the structure and properties.

Among the most important issues discussed are experimental data, and theoretical and computer models concerning deformation mechanisms in nanostructured materials, which, in general, are different from those in conventional coarsegrained materials. The competition between conventional and unusual deformation modes is believed to cause the unique mechanical properties of nanomaterials, serving as a basis for their structural applications. Fabrication of nanomaterials with bimodal (nano- and micrograined) composite structures, that exhibit both very high strength and reasonable ductility, represents a promising strategy in synthesis of nanomaterials with enhanced mechanical characteristics for various applications. High strain rate and low-temperature superplasticity of some nanocrystalline materials are the subject of growing fundamental research efforts motivated by a range of new applications of these superstrong and superplastic materials in netshaping technologies.

Symposium Support: ONR.

\section{Materials Behavior and Device Issues Explored at Micro-, Nano-, Molecular Scale}

(See MRS Proceedings Volume 741)

Symposium J on NEMS and MEMS was devoted to the understanding of materials behavior and device issues at the micro-, nano-, and molecular scale as well as the behavior and interface between micro-, nano-, and molecular devices. New materials and applications for micro- and nanosystems were introduced, and ongoing issues such as mechanical reliability, surface effects, processing and packaging issues, biocompatibility, and stability were discussed.

Invited presentations spanned a range of issues. S.P. Davis (Georgia Tech) gave a presentation on the fabrication, form, and function of microneedles for transdermal drug delivery. A.M. Belcher (Univ. of Texas, Austin) described the biological control and assembly of semiconductor and magnetic structures. Of particular interest were recent results showing the use of phage display (a method to biologically screen exhaustive random libraries of peptides on the surfaces of engineered viruses called bacteriophage) of peptides to control the nucleation and growth of semiconductor and magnetic nanoparticles from solution. B. Gates (Harvard) gave a presentation on behalf of $\mathrm{Y}$. Xia (Univ. of Washington) on novel methods of micro- and nanofabrication, with an emphasis on soft lithography. J. Jacobson (MIT) discussed applications for remote control, using radio-frequency energy, of DNA and protein molecular machines. C. Gerber (Univ. Basel, Switzerland) reported that fmoles of DNA have been detected on cantilevers with a DNA concentration in solution of $75 \mathrm{nM}$. This work 
was particularly well received because of the widespread use of cantilevers to measure mechanical properties of thin films by other participants - those methods now have new applications. J. Hormes (LSU) gave a review of current work and issues for LIGA fabrication of materials. L.J. Whitman (NRL) discussed the development of optical and giant magnetoresistive (GMR) magnetic-field biosensors. He reported that the GMR sensor has successfully detected $1 \mathrm{fmol}$ of DNA in a $30-\mu \mathrm{L}$ sample. C.T.-C. Nguyen (Univ. of Michigan) reviewed recent progress in the research and development of microelectromechanical devices for use in communication subsystems. O. Auciello (ANL) discussed recent results on ultra-nanocrystalline diamond for tribological and MEMS use.

S.L. Anna (Harvard) presented recent results with the use of flow focusing in microfluidic channels to form micro- and nanodroplets (emulsions) of water in an oil environment. P. Mach (Lucent/Bell Labs.) presented devices that combine microfluidics and micro-optics to dynamically tune the transmission characteristics of optical waveguides for attenuators and switches. The tunability was created using electrowetting pumps and recirculating planar microfluidic networks.

One of the highlights of the symposium was a tutorial presented by J. Bernstein (Corning-IntelliSense), T. Kenny (Stanford), M. Madou (Nanogen), and A.A. Ayón (Sony Semiconductor) on fabrication, sensing, biomimetics, and optical-MEMS and NEMS.

Symposium Support: Applied MEMS, Carl Zeiss, Harris \& Harris Grp., Ion Optics, Network Photonics, Sensors, Sony Semiconductor, Surface Technology Systems, and Tousimis Research Corp.

\section{Advances in SiC Materials, Processes, and Devices Unveiled}

\section{(See MRS Proceedings Volume 742)}

Symposium $\mathrm{K}$ is the second in a series of $\mathrm{SiC}$ symposia at the MRS Fall Meeting. Since the last meeting in 2000, advances in $\mathrm{SiC}$ materials, processing, and device design have resulted in implementation of SiCbased electronic systems and offer great promise in high-voltage, high-temperature, high-frequency applications. Presenters focused on new developments in the basic science of $\mathrm{SiC}$ materials as well as rapidly maturing device technologies. The challenges in this field include understanding and decreasing defect densities in bulk $\mathrm{SiC}$ crystals, controlling morphology and residual impurities in epilayers, optimization of implant activation and oxide-SiC interfaces, and developing novel device structures.

Topics of particular interest were in the area of bulk $\mathrm{SiC}$ growth (including largediameter crystals), modeling, characterization, homo- and heteroepitaxial growth (e.g., doping control, morphology development, and carrier lifetimes), advances in ion implantation, improved ohmic and rectifying contacts, surfaces and interfaces, oxidation, and alternative dielectric materials and devices (including highvoltage, high-temperature, high-frequency sensors and system level benefits).

Symposium Support: ARL, NASA Glenn Research Ctr., and ONR.

\section{Innovations Announced in Nitride- Based Semiconductor Technology and Materials Characterization} (See MRS Proceedings Volume 743)

In Symposium L on GaN and Related Alloys, recent results on growth and characterization of III-nitride semiconductors and their application in optoelectronic and electronic devices were reported. Several advances were reported in nitride-based technology for visible and UV-light emitters. Researchers at the University of South Carolina presented results on LEDs operating at $250 \mathrm{~nm}$, while NTT researchers presented 350-nm UV LEDs with maximum external efficiency of $1.4 \%$; phosphor-coated red and white LEDs incorporating their UV LEDs were also described by NTT. Lumileds researchers discussed the performance of their latest Luxeon LEDs, which achieve external quantum efficiency of $25 \%$ and $10 \%$ at $450 \mathrm{~nm}$ and $530 \mathrm{~nm}$, respectively. In addition, Lumileds presented a demonstration of backlighting using 34 Luxeon chips to create a full-color light source with color temperature up to $15,000 \mathrm{~K}$.

A number of notable results in the nitride materials characterization arena were presented, particularly with regard to defect structure and the behavior of $\mathrm{Mg}$ in p-doped GaN. Continued advances were also reported in the development of nitride-based electronic devices. New materials and device designs for nitridebased heterostructure FETs, targeted for rf power applications, were presented by several research groups. Included among these was a discussion of advances in the growth and fabrication of nitride electronic devices on Si substrates. Also reported were initial results on an AlGaAs-GaAsGaN heterostructure biopolar transistor realized using a wafer fusion process for device fabrication.

Symposium Support: AFOSR and ONR/DARPA.

\section{Progress Reported on Electronic and Optoelectronic Applications of Semiconductor Materials (See MRS Proceedings Volume 744)}

The first day of Symposium M on Progress in Semiconductor Materials IIElectronic and Optoelectronic Applications focused on the electronic applications of semiconductors with two sessions devoted to electronic devices. B.E. Landini (Kopin, Taunton, Mass.) reviewed the performance characteristics of InGaP/GaAs heterojunction bipolar transistors. Diluted nitride materials, or narrow-bandgap nitrides, and their applications were presented in an invited talk by C.W. Tu (UCSD). The latest progress on BiCMOS technology was sum-

\section{Volunteer Work, Risk-Taking Propel Powell's Career}

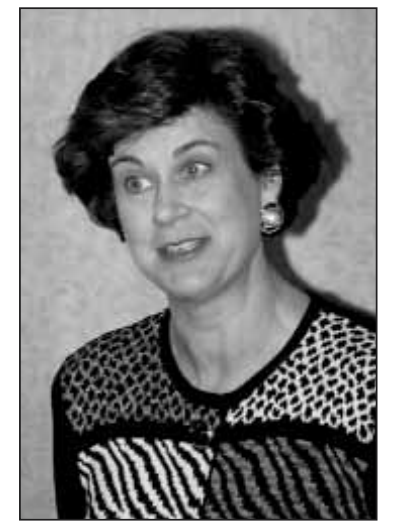

Lura Powell

Lura Powell, director of Pacific Northwest National Laboratory, spoke about taking risks in career path choices. At the Women in Materials Science and Engineering Breakfast, Powell described how volunteer activities in not-for-profit organizations and risk-taking propelled her career. When she studied chemistry in college, Powell did not have "leadership" in mind, but she was asked to lead a volunteer task, which prepared her for such positions in her career. She said that she became a federal employee by accident-what began as a summer position at the Bureau of Standards (now NIST) became a career move that lasted for several years. At the Bureau, Powell was instrumental in establishing on-site childcare before it became the norm. From this volunteer work, she built relationships with highlevel political players which made her a viable candidate to head the Advanced Technology Program at NIST, and from there to PNNL. The Breakfast was sponsored by the MRS Public Outreach Subcommittee, the Colloid and Surface Chemistry Division of the American Chemical Society, and Aldrich Chemical. 
marized by S.G. Thomas (Motorola), and the subject of SiGe BiCMOS for both electronic and optoelectronic applications attracted attention.

In the session on $\mathrm{ZnO}$ and related compounds, issues involving MBE growth of $\mathrm{ZnO}$ were presented by M. Yano (Osaka Institute of Technology, Japan), while doping and charge functionality were discussed by D. Norton (Univ. of Florida). New topics on the growth, doping, and optical and electrical characterization were discussed by many presenters. In the session devoted to the progress on emitters, lasers, and photovoltaics, J.M. Fitz-Gerald (Univ. of Virginia) presented an invited talk on UV-emitting SrS:Te thin films. A. Soibel's (Lucent/Bell Labs.) presentation on the quantum cascade laser attracted much attention. Other topics discussed were Sb-related quantum structures, codoping of GaAs, bonding and layer transfer, and light and heat patterns in infrared-emitting devices.

During sessions on nanostructures, J.S. Speck (UCSB) spoke on the progress in self-assembled quantum-dot lattices and S. Tanaka (Hokkaido Univ., Japan) talked about the formation of self-assembled quantum dots of quasi-lattice-matched
$\mathrm{GaN} / \mathrm{AlGaN}$ quantum dots. Interdiffusion in quantum wells and dots is a very important topic. H.H. Tan (Australia National Univ.) addressed the recent progress in interdiffusion in quantum-dot structures for photonic integrated circuits. Other presentations were devoted to various topics on the growth and characterization of quantum dots.

Normal incident photodetectors based on quantum dots have been the subject of various research groups during the last several years. This subject was presented by Z. Chen (Univ. of Southern California) followed by another talk on the theoretical progress of quantum-well detectors by C.Z. Ning (NASA Ames Research Center). F. Fuchs (Fraunhofer-Institut für Angewandte Festkörperphysik, Germany) discussed infrared detectors based on InAs/InGaSb short-period superlattices. J.M. Dell (Univ. of Western Australia) gave an overview of $\mathrm{HgCdTe}$ photodetectors. In the area of diluted nitride materials and quantum structures, J. Wagner (Fraunhofer-Institut für Angewandte Festkörperphysik, Germany) discussed the incorporation of nitrogen in InGaAsN. A.J. Steckle (Univ. of Cincinnati) discussed recent progress on rare-earth-doped GaN thin films and on the fabrication of electroluminescent devices. M. Holtz (Texas Tech Univ.) covered AlN-based superlattices for UV LEDs.

Symposium Support: AFOSR and AFRL/VSSS.

\section{High-к Gate Dielectrics: Race Against the Clock ...}

\section{(See MRS Proceedings Volume 745)}

Symposium N on Novel Materials and Processes for Advanced CMOS provided an overview on high- $\kappa$ dielectrics for gate applications, among other topics such as $\mathrm{SiGe}$ and Ni silicides. As presented in the plenary talk, the "sea of red" in the International Technology Roadmap for Semiconductors involves issues of gate dielectric and electrode. Given the pace of ULSI scaling, there is barely time remaining to reconsider the current material choices-Hf-based dielectrics are cited most often as the prime candidate to replace $\mathrm{SiO}_{2}$.

Besides Hf-based materials, a broad range of alternative materials (e.g., $\mathrm{Y}_{2} \mathrm{O}_{3}$, $\mathrm{LaAlO}_{3}, \mathrm{Pr}_{2} \mathrm{O}_{3}$ ) and deposition techniques (CVD- and MBE-based) were discussed. It became more than apparent during the various presentations that there are still major hurdles to overtake that involve materials issues such as crystallization

\section{China, Europe, Japan, South America, USA Presented International Collaboration Opportunities in Materials Research}

The seminar on International Opportunities in Materials Research, held over two evenings, was designed to encourage closer collaborations between MRS members worldwide and to provide information about collaborative research programs run jointly by funding organizations from different parts of the world.

Tom Weber, director of the Division of Materials Research at the National Science Foundation (USA), described criteria to obtain funding. He said that there is a "value-added" component when proposals include international cooperation. He described NSF-sponsored international workshops on materials for which the goal is to enhance collaboration in research, education, and technology. Industry in the United States tends to want scientists with international experience, he said, and the NSF workshops are geared toward developing the next generation of materials researchers. John B. Hunt, acting assistant director of the Mathematical and Physical Sciences program at NSF, described the development of virtual institutes and the Internet-based Materials World Net, promoting international collaborations.

He Minghong of the National Natural Science Foundation of China (NSFC) highlighted the priorities in materials science within the agency's five-year plan. He said the "major plan" focuses on photonic and electronic functional materials and on nanoscience and technology. These are two of a number of areas, however, supported by the agency's Engineering and Materials Science division. Minghong said that funds for materials make up nearly $10 \%$ of the total NSFC budget, which is the highest amount after the life sciences. International cooperation and exchange make up $15 \%$ of the total NSFC budget and the agency has 55 international cooperation agreements.

Guillermo Solózano of Pontificia Universidade Católica do Rio de Janeiro in Brazil covered Brazilian programs for international collaboration funded at the federal and state levels. The federal agency CNPq supports bilateral agreements with countries from South America, Europe, and Asia, and shares support for multilateral agreements with two other federal divisions, CAPES and the Ministry of Foreign Affairs. CIAM is a program specifically on inter-American collaboration on materials. Basically, the Ministries of Science and Technology and of Education support the federal programs while a number of science and technology agencies support state programs. Over the years, funding of science and technology in Brazil has been inconsistent. A Brazilian initiative, funded by $\mathrm{CNPq}$, is in nanoscience and technology. Recommendations have been made for funding of this area to be given from across the agencies.

From the European Commission, Ezio Andreta summarized the Sixth Framework Programme of the European Union, saying that anyone in the world can apply to such programs. Koichi Kitazawa, newly in the position of vice president of the Japan Science and Technology Corp., cited opportunities for exchange of researchers, bilateral and regional meetings, and collaborative research programs. When audience participants expressed interest in concrete examples of how such programs can work, the panelists acknowledged the difficulties in aligning programs, but suggested the best way to move the programs forward is to find a counterpart in another country, and then drive the process ahead. 
behavior, thermodynamic stability versus kinetically driven processes, oxygen stoichiometry, and interface control. Also, after transistor integration, issues remain with direct tunneling, boron penetration, control of the threshold voltage, fixed charges, and charge trapping as well as mobility degradation.

In regards to mobility, an excellent materials perspective was presented about the role of remote phonon scattering. Intrinsic to high- $\kappa$ materials is the presence of soft optical phonons, which are expected to exhibit long-range dipole coupling with surface plasmons, thus causing an effective reduction in effective electron mobility.

Furthermore, it was shown that CMOS-compatible poly-gate processes exhibit strong interaction with many of the high-к materials. These issues of integrating poly (crystalline) silicon as gate electrodes raise the importance of metal gate electrodes. Combined with an absence of gate depletion and the possibility of adjusting the threshold voltage without more threshold implants, these metal electrodes might find their way into transistors sooner than anticipated a few years ago.

Symposium Support: ASM Intl., ASML USA, and Kojundo Chemical Lab.

\section{Microphotonic Developments Excel in Areas of Slab-Type 2D Photonic Crystals and Photonic Wires}

Symposium $\mathrm{O}$ covered micro- and nanophotonic structures, various methods of their fabrication, their optical properties, and future device applications. It is an active and very broad area of research spanning from self-assembly of colloids to microstructured fibers, optics of plasmons in metallic nanostructures, and fabrication of various types of photonic crystals. Among the highlights reported in the traditional areas of this field were the demonstration of metallodielectric photonic crystals (Utrecht Univ., Netherlands), the development of a polymer microstructured fiber (Univ. of Sydney, Australia), the demonstration of frequency-selective thermal emission from a metallic photonic crystal (SNL), and the fabrication of a 3D photonic crystal by a nanorobotic technique (Madrid Univ., Spain).

This year's symposium focused mainly on two closely related fields: the development of slab-type 2D photonic crystals and high-refractive-index waveguidesso-called photonic wires. The idea of making ultracompact chip-scale photonic integrated circuits is the driving force behind the development of both of these technologies. Recent developments on low-loss ridge waveguides (MIT) and efficient bends and splitters (Columbia Univ.) on silicon-on-insulator materials were reviewed in a series of invited talks, which set the directions for the future in this rapidly growing area.

Two-dimensional slab-type photonic crystals represent another approach to photonic integrated circuits, which can provide the ultimate confinement of light down to the diffraction limit. Strongly enhanced light-matter interaction resulting from this confinement was shown to be the origin of efficient lasing in a photoniccrystal nanolaser as demonstrated by the Caltech group and the KAIST group (Korea). C. Weisbuch (Ecole Polytechnique, France) and T.F. Krauss (Univ. Glasgow, UK) highlighted the necessity of engineering and designing the specific geometry of photonic-crystal circuits to

\section{Symposium X Stretches Interdisciplinary Boundaries of Materials Research}

Film captures a slice of history in the making, yet the film itself has a history of its own. In Symposium X on Frontiers of Materials Research providing reviews for the nonspecialist, Michelle Aubert, curator for the French Film Archives of the National Center of Cinematography, described the challenges of film archiving. Beyond the intentional destruction and reuse of film to save space and reclaim materials, film can also degrade due to aging and environmental stresses. Archives to preserve film emerged in the 1930s, in part a response to destruction of silent films as sound entered the picture. Cellulose nitrate was an industry standard until 1950 due to its mechanical, physical, and picture qualities, although it had problems of flammability. It was replaced by cellulose triacetate, although this material-if stored improperly or if chemical residue remained-suffered from "vinegar syndrome" in which the film grew limp and acetic vapors escaped. Polyester is used in more recent film. A challenge in restoring film is in understanding the lighting and sound of the time so that restoration recreates these attributes. For the future, the effects of digital media are yet to be fully explored.

Materials and art meet again in a presentation by condensed-matter physicist Charles M. Falco (Univ. Arizona), who was a co-curator of an exhibit called "The Art of the Motorcycle," which went on display first at the Guggenheim Museum. Choosing artifacts for the exhibit based on their technological significance, Falco described the key role materials have played in the development of the motorcycle over the past 140 years. Falco said that the design of racing motorcycles, in particular, has a great likelihood of incorporating advanced materials to keep the weight down and speed up since cost is of minor concern.

Techniques used in materials research appear in other realms as well. David F. Rendle (U.K. Forensic Science Service, London) discussed the use of x-ray diffraction in forensic science, including the techniques of $x$-ray powder diffraction, $x$-ray fluorescence, and x-radiography. In one of several studies involving the use of $x$-ray diffraction, Rendle discussed a case that involved a burglary in which a key was obviously used to enter the building. There were only three keyholders. One came under suspicion and an analysis of his key yielded minute quantities of a white powder. X-ray analysis revealed that the powder was cuttlefish bone (arragonite), which is widely used to make impressions of keys for replication. A search of the suspect's house yielded a sample of cuttlefish bone, clinching the case.

In another Symposium X talk, Paul L. McEuen (Cornell) described work on the electrical, electromechanical, and electrochemical properties of individual nanotubes and single molecules, addressing recent interest in nanoelectronic devices wherein individual carbon-containing compounds are the primary electronic element. McEuen covered three examples wherein nanoelectronics meets mechanics: single-molecule transistors, suspended nanotubes, and single-electron atomic force microscopy. Nanotubes, he said, are proving to be excellent systems for the study of the physics of materials at the nanometer scale.

Hideo Ohno (Tohoku Univ.) discussed ferromagnetism and spintronics in semiconductors, introducing the concept of semiconductor magnetoelectronics or quantum information technology in which charge and spin would be used together. Materials such as one of the III-V ferromagnetic semiconductors and heterostructures, for example, $(\mathrm{Ga}, \mathrm{Mn}) \mathrm{As}$, could be used to explore the field. On another aspect of spintronics, Arthur Epstein (Ohio State) covered organic-based magnets. Look for articles based on some of these presentations in future issues of MRS Bulletin. 
minimize the losses and obtain required functionality. Several talks covered recent advances in developing a theory of adiabatic mode conversion for the case of periodic structures and efficient coupling of light into photonic-crystal waveguides.

Symposium Support: DARPA.

\section{Theoretical to Experimental Examples of Spin Injection Leave Further Challenges}

Symposium P, Novel Aspects of Spintronic Materials and Devices, provided an overview of challenges and recent progress in controlling the spin degrees of freedom in solid-state systems. It is instructive to think of a spintronics scheme as consisting of three different stages: generation of spin polarization, spin manipulation, and spin detection. Spin polarization can be defined as the ratio of the sum and the difference of spin-resolved components (spin-up and spin-down) of a particular quantity such as charge current, carrier density, or the density of states. While many materials in their ferromagnetic state can have a substantial degree of equilibrium carrier spin polarization, this alone is not sufficient for spintronic applications that typically require current flow and/or manipulation of the nonequilibrium spin (polarization).

A large part of the symposium focused on the issues related to spin injection where, by driving electrical current across the interface between magnetic and nonmagnetic material, nonequilibrium spin polarization is introduced in a nonmagnetic material. Detailed theoretical considerations were presented by R.H. Silsbee (Cornell) and E.I. Rashba (SUNY-Buffalo). Experimental reports on spin injection spanned a wide range of materials, from organic semiconductors (C. Taliani, ISM, Bologna, Italy) to HTSs

\section{Magnetoelectronics of Nanostructures Sports Healthy Debate \\ (See MRS Proceedings Volume 746)}

The area of anisotropic magnetotransport in magnetic superlattices (see Figure 1) remains controversial and intensely investigated by theorists and experimentalists, as demonstrated in Symposium Q on Magnetoelectronics-Novel

a

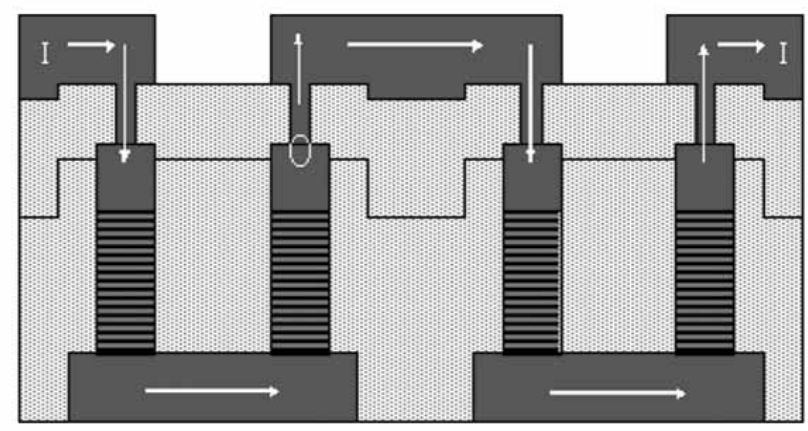

$\equiv \mathrm{Fe} / \mathrm{Cr} \square \mathrm{Nb} \quad \square \mathrm{SiO}_{2}$

b



Figure 1. Anisotropic giant magnetoresistance (GMR) measurement in Fe/Cr superlattices. (a) Geometry for the measurement using superconducting $\mathrm{Nb}$ leeds, and (b) comparison of GMR between the current-in-plane (CIP) and current-perpendicular-toplane (CPP) geometries. Note that the CPP GMR is about a factor of four larger than the CIP.
Magnetic Phenomena in Nanostructures. The main issues that were highlighted are the importance of mean free path, the connection between structure and GMR, and whether GMR originates from the bulk or interface in the superlattice, especially in experiments in which the current flows perpendicular to the interfaces. B.J. Hickey (Leeds Univ.) said, based on experiments in Permalloy-containing superlattices, that the mean free path is crucial in determining the GMR. Theoretical work (P. Weinberger, Univ. of Vienna) seems to show that in the $\mathrm{Fe} / \mathrm{Cr}$ interface, scattering originates in the interface in agreement with experimental claims (J. Santamaria, Univ. of Madrid, Spain).

The magnetic proximity effect, while an old subject, has received renewed attention from experimentalists and theorists who are principally motivated by the developments in spintronics. M. Kiwi (Catholic Univ., Chile) summarized the long history of this field. Generally, it is accepted and found experimentally (A. Hoffmann, ANL) that the magnetic proximity effect is small and confined to a very short distance close to the interface. A novel type of proximity effect was predicted theoretically (L.J. Sham, UCSD) in which electrons in a semiconductor become polarized if reflected from an interface with a magnetic material.

Exchange bias, while discovered almost 50 years ago, is still mysterious and thus intensely investigated. The exact origin, whether there is a single mechanism, and the connection to other physical and structural properties are researched by many groups worldwide, especially in antiferromagnetic/ferromagnetic (AF/F) bilayers. E.D. Dahlberg (Univ. of Minnesota) gave criteria for the magnetization reversal in $\mathrm{MnF}_{2} / \mathrm{Fe}$ bilayers and discussed the connection between reversal asymmetry and a threefold magnetic anisotropy found in this system. This is very unusual since most magnetic materials exhibit a symmetric reversal mechanism. M.D. Stiles (NIST) elaborated on the origin of the coercivity enhancement in polycrystalline AF/F bilayers. The random orientation of the AF easy direction from grain to grain yields an inhomogeneity and frustration of the F magnetization during reversal which enhances the coercivity. C. Leighton (Univ. of Minnesota) could experimentally demonstrate that the critical AF-layer thickness below which the exchange bias breaks down scales with the AF anisotropy. T.C. Schulthess (ORNL) discussed a theoretical model in which the symmetry of the $90^{\circ} \mathrm{AF} / \mathrm{F}$ coupling is broken by introducing an anisotropic exchange term (Dzyaloshinskii-Moriya interaction), which accounts for different random interfacial exchange configurations.

Symposium Support: ARO and ONR. 
(J. Wei, Univ. of Toronto). It was shown that metallic ferromagnets combined with a tunneling barrier can provide efficient room-temperature spin injection into common semiconductors such as GaAs (B.T. Jonker, NRL and V.I. Safarov, Univ. Aix-Marseille II, Marseille, France).

An alternative method to inject spin into GaAs was discussed by S.S.P. Parkin (IBM Almaden Research Center). His technique employed a magnetic tunneling transistor, which is a three-terminal device combining a magnetic tunnel junction with a semiconductor collector.

However, many materials challenges remain: A substantial injection of spin into silicon has yet to be demonstrated and the race to fabricate a reliable roomtemperature ferromagnetic semiconductor continues.

Symposium Support: ONR.

\section{Sensitive Measurements Advance Characterization of Artificially Structured Magnetic Systems (See MRS Proceedings Volume 746)}

Parallel advances in the tailored synthesis and characterization of artificially structured magnetic systems has fueled continued research into a broad range of properties at both fundamental and applied levels. Symposium $\mathrm{R}$ focused on recent advances in the development and application of sensitive measurements that provide insight into a range of magnetic phenomena in these systems.

Understanding magnetic structure and interactions at and across interfaces remains of great interest. Spatial variations in magnetic structure and properties both in depth and laterally are of interest. Nonlinear magneto-optical- and photoelectron-based techniques are highly interface- or surface-sensitive in such systems, while $\mathrm{x}$-ray and neutron reflectometry can probe magnetic structure more deeply into thin-film samples.

Lateral resolution of magnetic (and chemical) structure is obtained by many different tools having complementary sensitivity and applicability. Capabilities of scanning probes such as MFM and spin-polarized STM continue to improve. Diffuse magnetic scattering of resonant $x$-ray (and visible) photons and neutrons probes lateral structure with spatial resolution close to the probe wavelength. Sophisticated new approaches to imaging magnetization with transmission electron microscopes and with photoelectron-emission microscopes at synchrotron radiation facilities continue to be developed.

Magnetization dynamics and spin excitations, especially in confined systems, are well studied by pump-probe magneto-

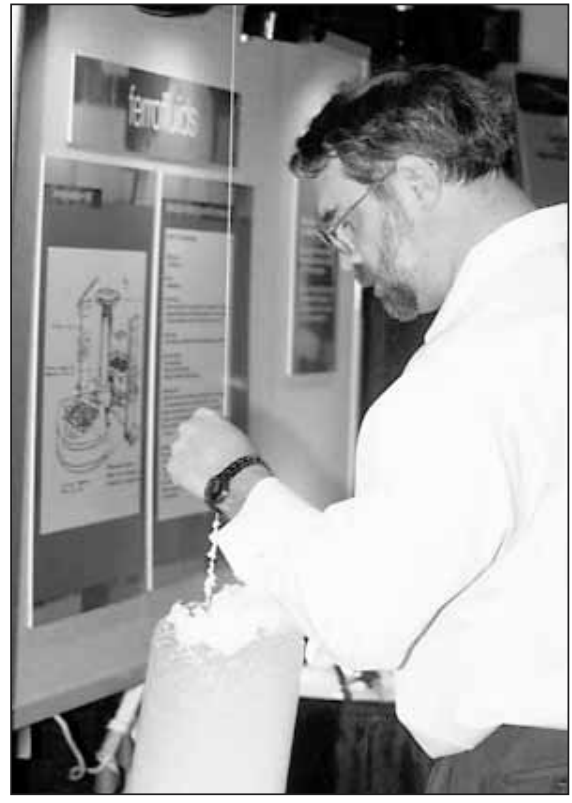

An attendee tests a science exhibit prototype of foam that travels up a wire based on capillary forces. This is part of the MRS Materials MicroWorld project funded in part by the National Science Foundation. Several prototypes of possible exhibits were displayed for comments at the 2002 MRS Fall Meeting. optical imaging, Brillouin light scattering, and FMR techniques. The structure and damping of spin excitations and their interactions with external stimuli are all of great interest.

Symposium Support: ANL, JEOL USA, LANL, LBNL, Natl. High Magnetic Field Lab., NIST, and ORNL.

\section{Progress Made in Superconductivity from Materials Research at Nano- and Decameter-Length Scales}

A central theme in the development of HTS applications is the pervasive role of structure-composition-property correlations on the nanometer scale. The unknown (and initially, unsuspected) nature of these correlations previously had blocked rapid implementation of HTS cuprates. Sixteen years after cuprate superconductivity was first discussed at an MRS Fall Meeting, however, through continued research, these nanoscale property relations have become the guiding principle for material design and nascent technology development. Both aspects, basic and applied, formed the impetus of Symposium $S$ on Advances in Superconductivity. A second focus was the fast-moving materials science of the "new" superconductor $\mathrm{MgB}_{2}$. A tutorial provided background to the physics and processing of $\mathrm{MgB}_{2}$ and to

\section{High School Students Introduced to Electronic Fabrics}

Students from three Boston area high schools attended this Fall's student workshop sponsored by the MRS Public Outreach Subcommittee. Margaret Orth, of International Fashion Machines, and Tricia Wilson, of Foster-Miller, Inc., introduced their young audience to the science of electronics on nonconventional substrates and the engineering challenges to integrate electronic functionality into comfortable, fashionable clothing and decorative textiles. Approximately 30 students from The Roxbury Latin School, Commonwealth School, and The Boston Latin Academy, and their science teachers, participated in a series of mini-lectures, demonstrations, and hands-on activities presented by Orth and Wilson. The workshop concluded with a tour of the exhibit, pizza, and a chance to talk with graduate students from the MRS MIT Student Branch.

The Public Outreach Subcommittee organizes and presents these workshops to encourage high school students to pursue an academic path leading to a career in materials science. The event is sponsored by NSF and several very generous exhibitors.

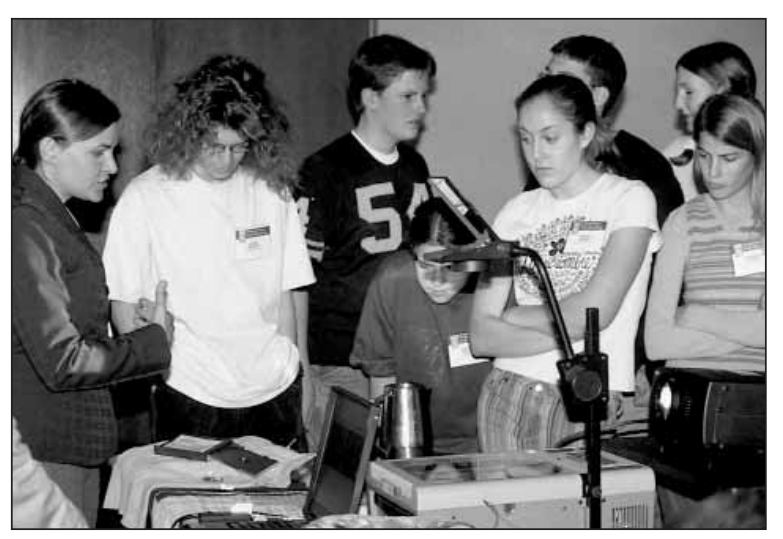

Maggie Orth (far left) demonstrates "electronic textiles" as part of this Fall's High School Student Workshop. Students from three local schools get a close-up view of a truly dazzling sweatshirt. 


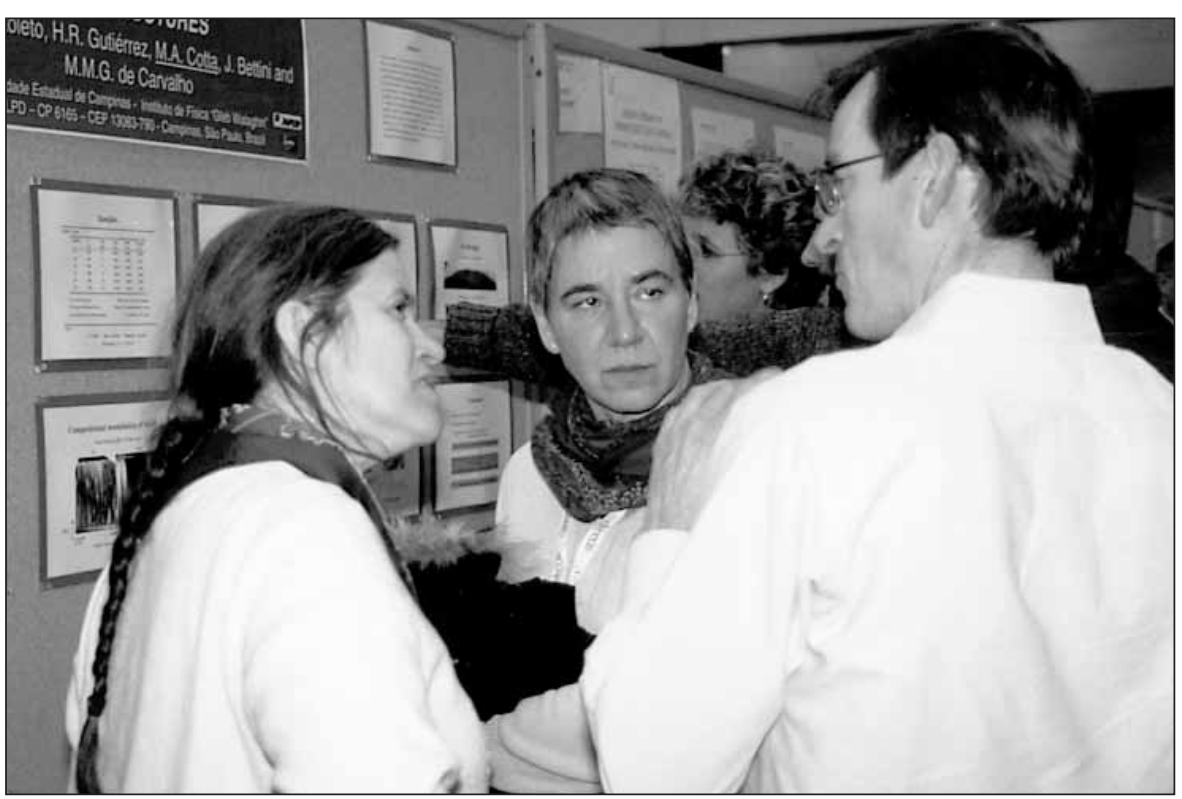

Poster sessions provided researchers with an opportunity to discuss their work.

the role of flux pinning for electric power and magnetic applications.

Remarkable progress was reported, using sophisticated techniques such as STEM-EELS, electron holography, and Lorentz microscopy, toward the elucidation of fundamental properties on the nanometer scale in the HTS cuprates. It was shown that targeted substitutions of $\mathrm{Ca}$ in $\mathrm{YBa}_{2} \mathrm{Cu}_{3} \mathrm{O}_{7}$ (YBCO) grain boundaries have the capacity to reduce the builtin interface potential, confirming the proposed mechanism for the supercurrent enhancement by such doping. Complimentary work highlighted the role of crystal chemistry and structure with respect to functional properties such as electronic anisotropy and flux pinning. Technological highlights included the superior transport properties achieved in YBCOcoated conductors, currently produced in tens-of-meters lengths at corporate laboratories worldwide through reel-to-reel processing, and the strong magnetic-field performance of certain mixed-rare-earth $\mathrm{RBa}_{2} \mathrm{Cu}_{3} \mathrm{O}_{7}$ (RBCO) melt-processed "pucks." Coated conductors are now regarded as the second-generation wire technology for electric power applications, following the successful but more expensive multifilamentary powder-in-tube composites. Plans were described for a demonstrator project in which a 30-m HTS cable based on YBCO-coated conductors is to be installed in an urban power grid in the next 2-3 years. The strong field performance of melt-processed RBCO is ascribed to an apparently optimized microstructure for flux pinning, consisting of an ordered modulation in the chemical composition on the nanometer scale. Commercial development of these materials is pursued for a wide range of applications, including water purification.

$\mathrm{MgB}_{2}$ research and development includes work toward practical utilization in the form of wires and electronic devices, as well as a search for new superconductors with related structure or chemistry. Several presentations highlighted the unique nature of $\mathrm{MgB}_{2}$ compared to other di-borides, in particular with respect to its stable composition. Superconductivity in $\mathrm{MgB}_{2}$ appears to be a model system for the study of superconductivity with two distinct energy gaps. Progress was reported on the controlled growth of $\mathrm{MgB}_{2}$ and cuprate epitaxial films, using in situ monitoring techniques.

Symposium Support: ANL, LANL, Neocera, ORNL, and Univ. of Wisconsin.

\section{Ferroelectric Thin Films Advance Toward Applications} (See MRS Proceedings Volume 748)

Substantial progress in integrated ferroelectric device technology was demonstrated in Symposium U, along with continuing developments in materials-processing techniques and the fundamental understanding of ferroelectricity in thin films. Several presentations highlighted advances made in the fabrication of highdensity ferroelectric nonvolatile memories. Presenters addressed a variety of subjects, including issues of materials integration, the effect of stress on capacitor properties, and long-term reliability. R. Bruchhaus (Infineon) described the latest results of a 32-Mb FeRAM fabricated in collaboration with Toshiba Corp. In addition, K.R. Udayakumar of Texas Instruments, with colleagues at Ramtron International and Agilent Technologies, discussed the operation of the highest-density FeRAM device fabricated to date. Significant progress on integrating $\mathrm{SrBi}_{2} \mathrm{Ta}_{2} \mathrm{O}_{9}$ capacitors over $\mathrm{W}$ contact plugs was addressed by $\mathrm{D}$. Wouters (IMEC).

Advances in the deposition of ferroelectric thin films were also highlighted, with several groups demonstrating very low switching voltages in both Bi-based and $\mathrm{Pb}$-based films. Investigation of epitaxial films, deposited on a wide variety of substrates, is also an area of active research by numerous groups. Significant progress was made recently on the deposition of ferroelectric thin films on $\mathrm{Si}$.

Presentations from D.A. Bonnell's group of the University of Pennsylvania described novel device concepts based on the definition of domain patterns in ferroelectric thin films, with controlled adsorption of metal particles at surface locations defined by ferroelectric polarization.

Research on the pyroelectric and piezoelectric properties of ferroelectric thin films has yielded promising results. H. Beratan (Raytheon), for example, described the materials issues associated with fabricating a pyroelectric imaging array based on La-doped PZT films. The presentation included a demonstration of high-quality images captured by a fully functional system. Use of ferroelectric thin films for a variety of piezoelectric MEMS applications was also described, with a survey of new materials for this application provided by S. Trolier-McKinstry (Penn State). Several presentations covered a novel approach for forming singlecrystalline ferroelectric films for piezoelectric and optical applications in which thin layers are separated from a bulk crystal by hydrogen or helium implantation and subsequently bonded onto the desired wafer. This method is an interesting alternative to traditional deposition techniques, and holds promise for integrating ferroelectric materials onto a wide variety of dissimilar substrates.

Some presentations addressed the use of high-permittivity materials for a variety of capacitor applications. Materials such as $(\mathrm{Ba}, \mathrm{Sr}) \mathrm{TiO}_{3}$ (BST) are of particular interest for use as decoupling capacitors, and highlighted by J.D. Baniecki (Fujitsu). Furthermore, the voltage-tunable dielectric constant of BST is being exploited for a variety of high-frequency applications. As such, 
the origins of high-frequency loss in BST and related materials are an area of active research. High-frequency applications also require the use of high-conductivity metallization, and progress on integrating highpermittivity capacitors with $\mathrm{Cu}$ was discussed. The effects of electrode interfaces and grain boundaries on the properties of $(\mathrm{Ba}, \mathrm{Sr}) \mathrm{TiO}_{3}$ thin films were also discussed in several presentations.

Symposium Support: Kojundo Chemical Lab., Seiko Epson Corp., and ULVAC.

\section{Morphological and Compositional Evolution of Thin Films Elucidated (See MRS Proceedings Volume 749)}

Advances in pattern formation, strain evolution, and nanostructuring of surfaces were reported in Symposium W on Morphological and Compositional Evolution of Thin Films. Kinetic pattern formation at surfaces was the subject of several talks. Recent developments in scaling theory and kinetic Monte Carlo simulations have furthered the understanding of how pattern structures depend on the kinetic parameters of growth. A report on InGaAs films grown on GaAs illustrated the complexity of pattern formation (J. Mirecki Millunchick, Univ. of Michigan). In that system, annealing the strained films leads initially to mound formation, then mound dissolution and the development of step bunches, and finally to the formation of vacancy islands.

Electrodeposition was highlighted. The close relationship between solidification dynamics and electrodeposition was outlined by J.E. Guyer (NIST) in a study of phase-field modeling of the electrochemical interface. A theory of the role of additives in controlling surface roughness during electrodeposition was described by D.J. Srolovitz (Princeton). It was shown that additives can suppress the development of roughness by preferentially bonding at surface protrusions.

New experimental results on lateral composition modulation (LCM) in thin films and superlattices were presented. For example, STM and $x$-ray scattering were used to probe the dependence of the modulation wavelength on film and superlattice properties (e.g., layer thickness) (R.S. Goldman, Univ. of Michigan). New theoretical analysis shows how the increase in surface stress that drives LCM is related to the perturbation wavelength, film thickness, and temperature (S.R. Lee, SNL).

Results from several experimental and theoretical investigations of Ge quantum dots were presented. Highlights included the determination of the shape, strain, and Ge distribution in both capped and uncapped dots using $x$-ray scattering $(\mathrm{J}$. Stangl, Johannes Kepler Universität, Austria), and the observation of four-dot quantum "fortresses" that nucleate at pits during SiGe heteroepitaxy (J.L. Gray, Univ. of Virginia).

Symposium Support: ELMITEC GmbH, IBM T.J. Watson Research Ctr., k-Space Assoc., and Omicron NanoTechnology USA.

\section{Interfacial Control Enables New Materials, Heterostructures for Oxide-Based Electronics (See MRS Proceedings Volume 747)}

Symposium V covered a wide range of topics involving the interfaces between electro-optical oxide layers and a variety of other materials. Overall, some of the key themes were the increasing integration of disparate materials such as oxides, organics, and semiconductors to produce devices with unique functionality. These devices span the range from epitaxial films to amorphous structures. In the former case, a group at the Tokyo Institute of Technology introduced an approach to producing epitaxial films $\left[\mathrm{InGaO}_{3}(\mathrm{ZnO})_{5}\right]$ by employing thin interfacial seeding layers (see Figure 1) and also demonstrated that amorphous $\mathrm{ZnRh}_{2} \mathrm{O}_{4}$ can be a good $\mathrm{TCO}$, raising the question of the potential of low-temperature deposition of functional TCOs. This could be important in another emerging area of oxide applications: organic electronics. T.J. Marks (Northwestern Univ.), G.E. Jabbour (Univ. of Arizona), and J.-L. Brédas (Univ. of Arizona) addressed the complex issues of organic optoelectronics where reduction of process temperature while optimizing the excitonic and electronic carrier mobilities necessitates intimate control of the interfacial properties in the device. These currently involve combinations of small molecules, polymers, oxides, metals, and chemical derivatization of the interfaces yielding a new level of complexity in interfacial phenomena.

The symposium also highlighted the increasing versatility of novel oxide materials in a wide range of emerging applications. Some of these include work by A.P. Ramirez (LANL) on the large dielectric constants in $\mathrm{CaCu}_{3} \mathrm{Ti}_{4} \mathrm{O}_{12}$, by $\mathrm{H}$. Hosono (Tokyo Inst. of Technology) and co-workers on the TCO properties of LaCuOS, by Y. Yoshida (Colorado School of Mines) on the high performance of InO:Mo as a TCO, by J.A. Misewich (IBM T.J. Watson Research Ctr.) on novel field-effect devices, among many others. Many of these structures necessitate intimate control of the interfaces to obtain optimum electronic and optical properties. This was a theme of the symposium and was nicely summarized in a talk by D.H.A. Blank (Univ. of Twente, The Netherlands) on controlling the growth and interfaces of complex oxide herterostructures. Overall, it is clear that a new generation of materials and heterostructures has been enabled by this increasing control of interfacial phenomena.

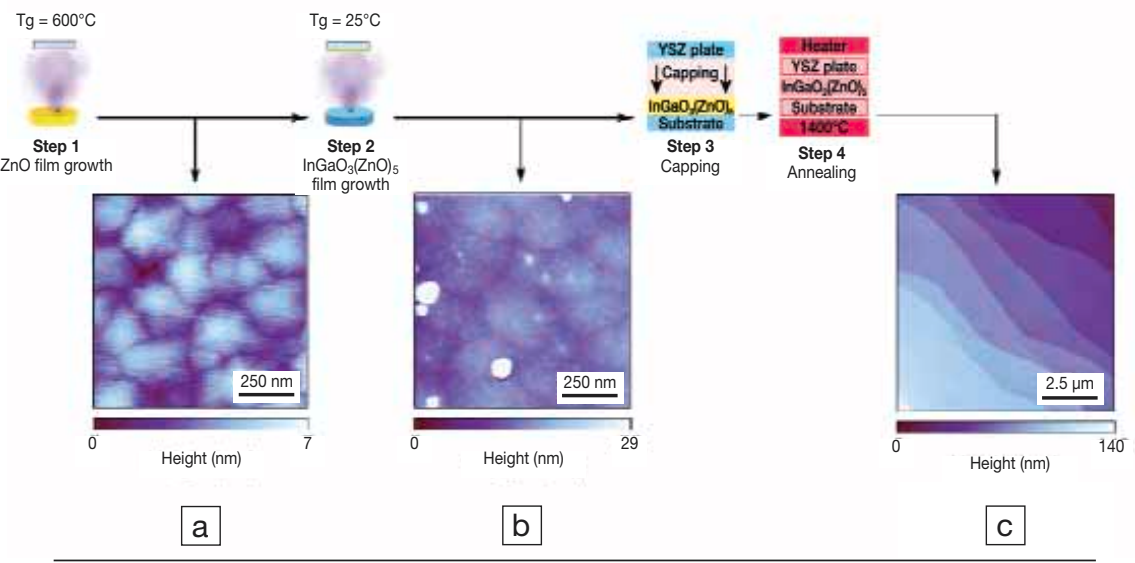

Figure 1. AFM images of (a) a ZnO epitaxial film on YSZ(111) substrate, (b) a bi-layered film composed of $\mathrm{InGaO}_{3}(\mathrm{ZnO})_{5}$ and $\mathrm{ZnO}$ epitaxial layers before annealing, and (c) after annealing at $1400^{\circ} \mathrm{C}$ in air. Schematic drawing of the reactive solid-phase epitaxy method is also shown. 
continuum-level modeling of materials and behaviors relevant to near-surface mechanical-property characterization, contact, and adhesion. Reflecting the importance of surface engineering to current and future industrial practices, a special session on industrial applications of surface engineering was again held, with contributions from academia as well as from several major U.S. and European manufacturing companies. For the second time, a joint session was held with the MEMS/NEMS symposium, highlighting surface engineering issues in MEMS structures and devices. Issues such as the potential application of nanocrystalline diamond materials to MEMS, tribology of LIGA alloys, and stiction of MEMS were discussed. A new session was added in this symposium dealing with bio/microelectronic applications.

Symposium Support: GM, Hysitron, JEOL $U S A$, and Micro Photonics.

\section{Science and Technology of Membranes Highlighted}

(See MRS Proceedings Volume 752)

Symposium AA on MembranesPreparation, Properties, and Applications offered an overview on the recent advances in the science of membranes and in emerging membrane technologies. A large effort is currently devoted to the development of new generations of membranes based on organic, inorganic, hybrid, or composite nanomaterials. The potential use of zeolite membranes for both gas and liquid separation has given rise to increas-

\section{Challenges and Successes in Understanding Surfaces and Interfaces: Some Pain for Considerable Gain \\ (See MRS Proceedings Volume 751)}

Surfaces and interfaces in oxides are unashamedly complex. In reality, their structures are irregular and need to be examined at an atomic level. Such an understanding is of paramount importance since future technological advances require it. Presentations in Symposium Z, on Structure-Property Relationships of Oxide Surfaces and Interfaces, focused on materials with periodic inhomogeneities that more closely resemble reality than earlier research on well-ordered systems.

In particular, among the highlights was a focus on the dynamical evolution of surface structure. Particularly exciting was the work of K.F. McCarty (SNL) who

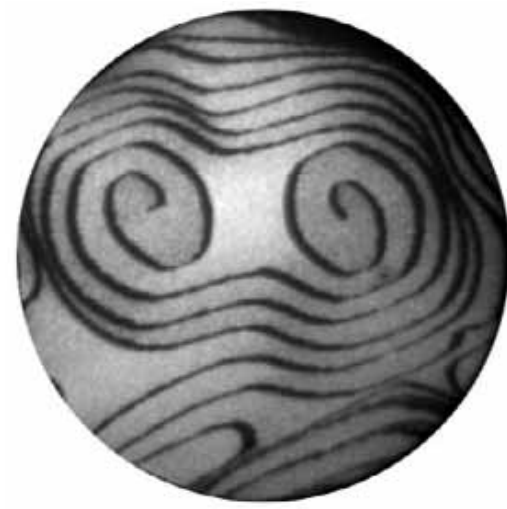

Figure 1. Stack of oval islands on a $\mathrm{TiO}_{2}$ surface spawned from two screw dislocations. used LEEM to show that the structure of the $\mathrm{TiO}_{2}(110)$ surface depended on the bulk defect density, which also controlled the growth and retraction of islands and pits (see Figure 1).

Such complex interplay between structure, chemistry, and environment is clearly challenging. Consequently, many presentations tackled such problems by using a combination of both experiment and simulation. An elegant example was provided by H.Y. Hwang (Lucent/Bell Labs) who used density functional calculations to confirm and provide an interpretation of EELS data on an atomic layer intergrowth of $\mathrm{LaTiO}_{3}$ in $\mathrm{SrTiO}_{3}$ (see Figure 2). Such synergy between theory and experiment underpins a maturing of approach to these most demanding of problems.

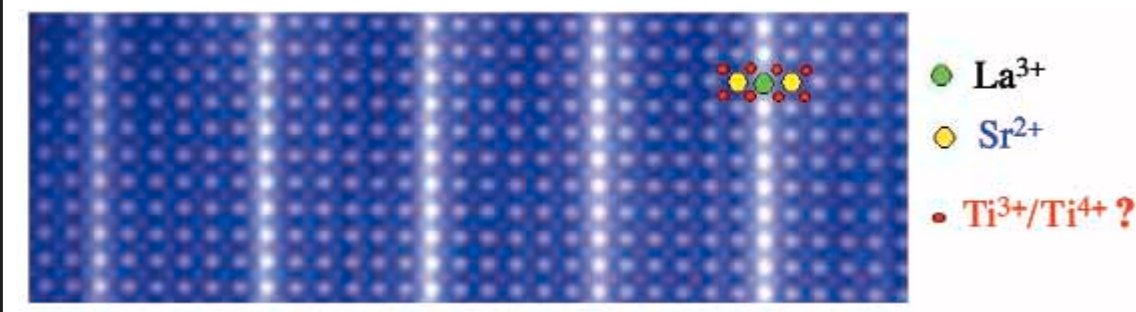

Figure 2. Atomic-scale delta doping in strontium titanate.

ingly intensive research activities in preparation methods and characterization. Templating effect, surface modification, and functionalization are used to optimize the permeability and permselectivity of the membranes. Technological achievements gained in microelectronics are applied to developing miniaturized separation devices and microsieves.

Innovative approaches were also presented on the characterization of the membrane microstructure and on the modeling of fluid transport through the membrane, contributing significantly to the understanding of the structure-to-properties interrelation. In addition to the improvement of currently available processes for liquid separation, novel applications to pervaporation, gas separation, membrane reactors, and biotechnology are already under way. New challenges and opportunities exist also for membrane applications in fuel-cell technologies and in the semiconductor industry.

Symposium Support: ICE/HT-FORTH and Praxair.

\section{Strength, Fragility, and Unifying Principles Examined in Bulk Metallic and Related Glasses}

(See MRS Proceedings Volume 754)

Symposium CC on Supercooled Liquids, Glass Transition, and Bulk Metallic Glasses broadened the scope from previously held symposia to consider nonmetallic glasses. The majority of the presentations addressed Zr- and Pd-based glasses with, surprisingly, little progress reported on Mg-based glasses. Even though BMGs based on Al still remain a grand quest, many presenters dealt with the synthesis and stability of Al-based glasses. The topic of iron-based glasses was also covered. W.L. Johnson (Caltech) discussed ultracentrifuging multicomponent alloys in the search for multi-eutectic compositions favoring BMG. It is evident that the mechanical properties of BMGs are attracting considerable attention with insights on shear bands. Progress was also reported on modeling the structure and flow of metallic glasses. Further evidence was presented linking the icosahedral order in quasi-crystals and some BMGs.

The three leaders of this field-A. Inoue (Tohoku Univ.), W.L. Johnson, and S.J. Poon (Univ. of Virginia)—addressed guidelines for the formation of BMGs. Inoue said that the key factors are size difference of the constituent atoms and heat of mixing. But overall, he emphasized that $\Delta \mathrm{Tx}$ is an important parameter for optimizing compositions for BMG formation. Johnson said that the most usual and useful guideline is the Turnbull criterion of high $T_{\text {rg }}$. Size differ- 
ence is also important. A size ratio of 0.8 promotes glass, while a larger difference (ratio of 0.7) promotes the formation of Laves and Frank-Kasper phases. The occurrence of these phases can be a good indication that a composition range is approaching that is promising for BMG formation. Poon addressed the complexity of BMG formation and discussed the need for an alloying strategy that includes careful selection of particular interatomic interactions.

The theme for the second discussion was the basis of fragility. It was led by C.A. Angell (ASU). He noted that there are several possible definitions of fragility. Three possible definitions were expressed and one was recommended. Angell emphasized the new insights coming from S. Sastry's (Jawaharlal Nehru Ctr.) energy landscape approach to the description of glass transition. Atomic/ molecular origins of strength/fragility were considered, particularly the need to consider interactions beyond the nearestneighbor shell. Comparisons focused on BMGs, chalcogenides, and silica.

Symposium Support: DARPA and Liquidmetal Technologies.

\section{Advancements Described in Study of Transition Metals in Solid-State Chemistry of Inorganic Materials (See MRS Proceedings Volume 755)}

Symposium DD, Solid-State Chemistry of Inorganic Materials IV, highlighted major advancements in areas including metal-to-insulator transition compounds; porous materials; nanomaterials; dielectric materials; and new methods of synthesis, crystal growth, and characterization. Novel nanoporous materials and the preparation of metastable perovskite films were reported. The technique of resonant inelastic $x$-ray scattering spectroscopy was introduced by K.E. Smith (Boston Univ.). The technique allows the determination of the electronic structure of polycrystalline and semiconducting/ insulating materials, which was possible hitherto only for metallically conducting single crystals with good surfaces by photoelectron spectroscopy.

A.R. Kaul (Moscow State) addressed epitaxial stabilization, which was known up to now as a phenomenological base for obtaining solutions of III-V semiconductors for many important applications. It now begins to play a role in obtaining new oxide materials. It was shown that the perovskites $\mathrm{RBO}_{3}$ can be stabilized against oxygen dissociation (in the $\mathrm{RNiO}_{3}$ and $\mathrm{RCoO}_{3}$ series) or against polymorphous transition to more stable phases. In particular, high-pressure perovskites $\mathrm{RMnO}_{3}$
$(\mathrm{R}=\mathrm{Ho}, \mathrm{Er}, \mathrm{Tm}, \mathrm{Yb}$, and $\mathrm{Lu})$ and $\mathrm{RInO}_{3}$ ( $\mathrm{R}=\mathrm{Eu}-\mathrm{Lu})$ were obtained at ambient pressure as epitaxial films on $\mathrm{LaAlO}_{3}$ and $\mathrm{SrTiO}_{3}$ substrates, respectively. The inbulk unstable hexagonal polymorphs of $\mathrm{RMnO}_{3}(\mathrm{R}=\mathrm{Dy}-\mathrm{Eu})$ were reported as epitaxial films on a YSZ(111) substrate. In the same way, hexagonal $\mathrm{RFeO}_{3}(\mathrm{R}=\mathrm{Eu}$ $\mathrm{Lu}$ ) of the ferroic space group $\mathrm{P}_{3} m c$ were obtained for the first time.

One of several facets of nanotechnology that was explored during the course of this five-day symposium concerned the recent development of nanoporous solids. Two exciting new classes of thermally stable porous solids were described, both containing transition metals.

Symposium Support: ACS and NSF.

\section{Insights into Ion Conduction Advance Lithium Batteries and Other Energy Technologies}

(See MRS Proceedings Volume 756)

Symposium EE, Solid-State Ionics, highlighted advancements in the domains of energy storage and conversion and environmental monitoring.

A session on the theory of ionic conduction demonstrated the potential of various simulation techniques (e.g., molecular dynamics, Monte Carlo, and $a b$ initio) for achieving an improved understanding of the mechanisms of ionic motion in solids (e.g., glasses, polymers, and inorganic crystalline systems). The session devoted to ionic conduction in nanostructured materials (i.e., nano-ionics) was another highlight of the symposium. It confirmed the paramount importance of interfacial phenomena for solid-state ionics. Spacecharge theory provided, for the first time, a quantitative description of electrical conductivity of $\mathrm{CeO}_{2}$ that is dependent on grain size.

The sessions on oxide electroceramics were focused on oxygen-permeation membranes, solid-state sensors, and solid-oxide fuel cells. The reports suggested that breakthroughs to commercial use are not far away, especially given impressive improvements in the mechanical properties of solid-oxide membranes.

The largest cluster of communications was devoted to new materials for advanced lithium batteries. Conventional wisdom held that only certain intercalation compounds can insert and de-insert lithium ions and can be used as anode and cathode materials. Recent experiments showed, however, that simple binary compounds, hitherto neglected in the search for better cathode and anode materials, such as $\mathrm{CoO}$, can reversibly exchange lithium ions if the particle size is sufficiently small. This is a major dis-

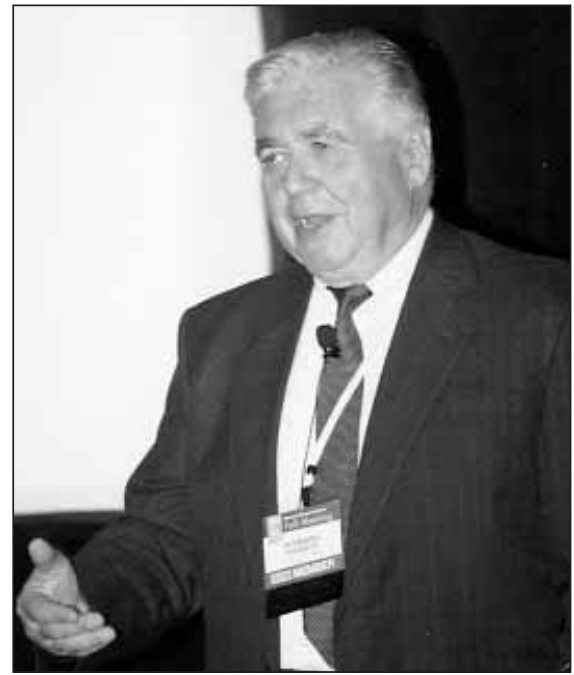

Howard Birnbaum (University of Illinois), recipient of the 2002 Von Hippel

Award, delivered his award talk about hydrogen effects on deformation and fracture in metals.

covery, implying that a large number of compounds have to be checked again from this point of view. Related to this development, nanostructured and nanocomposite solid electrolytes, especially polymer-based, were another strong topic of the symposium.

Symposium Support: Robert Bosch GmbH and SETNAG.

\section{Proton-Exchange Membranes, Methanol Among Developments Discussed in Fuel Cells and Fuel Processing}

(See MRS Proceedings Volume 756)

Symposium FF provided a multidisciplinary forum to discuss materials issues in the development of fuel cells and fuel processors. Such systems have application in battery replacement, vehicle propulsion, auxiliary power for transportation, defense, and distributed power. Discussions on fuel cells with proton-exchange membranes focused on novel inorganic-organic composite membranes, new membrane compositions that enable high-temperature operation, nanostructured electrocatalysts showing exceptionally high activity, progress in improving the corrosion resistance of bipolar plates, and efforts to commercialize bipolar plate technology.

Discussions relevant to solid-oxide fuel cells revealed new electrode and electrolyte compositions, novel thin-film synthetic routes, mechanisms of reactions responsible for electrode overpotentials, and innovative strategies for producing ceramic-metal seals. A new, bipolar plate- 


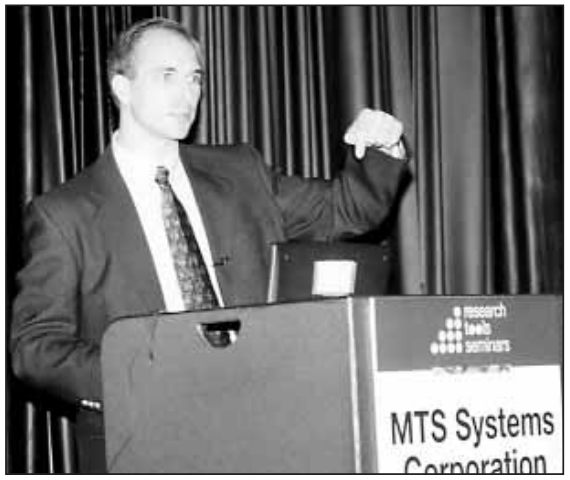

Vincent Jardret of MTS Systems Corp. (Oak Ridge, Tenn.) presented an educational Research Tool Seminar in the equipment exhibit hall on instrumented indentation testing, also referred to as nanoindentation, continuous recording indentation, depth- sensing indentation, low or ultralow load indentation, and picoindentation.

supported solid-oxide fuel-cell structure was introduced that offers improved mechanical stability. Fuel processing, necessary to convert hydrocarbon fuels into a form compatible with fuel cells, was a major topic of discussion. Catalyst compositions and forms for steam reformation, autothermal reformation, partial oxidation, water-gas shift, and preferential oxidation were described, and deactivation mechanisms addressed. Presentations on the formation kinetics and methods to manage sulfur compounds and ammonia were also given, including membrane separation. Microfuel cells and fuel processing systems were described, principally focusing on using methanol as a fuel.

\section{Thermal-Barrier Coating \\ Microstructure Studies Reported}

Symposium $\mathrm{HH}$ addressed thermalbarrier coatings (TBCs) and other hightemperature coatings, namely, process optimization and control, degradation and failure mechanisms, microstructurecoating property relationships, and coating optimization and characterization.

In the area of process optimization, novel processes were described for obtaining nanophase PSZ coatings. One of the processes involves suspension plasma spraying with a dc plasma torch, using nanoparticles dispersed in a liquid that is injected into the plasma jet ( $P$. Fauchais, Univ. of Limoges, France). The resulting coatings composed of smaller splats ( 75-nm splat thickness) have excellent thermal and mechanical properties. The relative advantages of the suspension spray process for obtaining controlled microstructure were discussed (L. Xie, Univ. of Connecticut and N. Bahlawane, Univ. of Bielefeld, Germany), and a double deposition process was described in which two hybrid dc jet stabilized rf plasma torches were mounted side by side, with a combined power of $\sim 330 \mathrm{~kW}$ (T. Yoshida, Univ. of Tokyo). One torch is used for depositing a coating by plasma spraying using regular powders; the other torch is used for simultaneous vaporphase deposition. The combination of the spray and CVD processes are improving control over the coating microstructure, in particular for nanophase coatings. The advantages of using nanophase PSZ coatings were also highlighted in a presentation by C. Berndt (SUNY-Stony Brook) which provided a map for processparameter selection for obtaining specific microstructures using conventional plasma spraying.

Approaches to process control were described by several speakers, mostly based on measurement of spray particle temperature and velocity, and relating them to coating microstructure (e.g., splat structure and crack formation).
In the session on failure mechanisms, C.A. Johnson (GE) described the effect of airborne contaminants (e.g., dust) that can deposit on the coating, forming oxides with relatively low melting points during exposure to the high temperatures, penetrating the coating and leading to a reduction in strain tolerance and to spallation. Several presentations dealt with stresses produced by thermally grown oxides, which were primarily a function of the number of thermal cycles rather than the temperature (S. Sridharan, Univ. of Connecticut), and with stresses generated by rumpling of the bond coat due to oxide formation (M. Madhwal, Univ. of Connecticut, and R. Panat, Univ. of Illinois).

Coating microstructure, and in particular pore structure characterization, was introduced by H. Herman (SUNYStony Brook) with a review of different microstructures and the most recent characterization techniques, including x-ray microtomography giving 3D images of portions of the coating, and small-angle neutron scattering. Further presentations described additional details of these techniques, applied to a variety of specific

\section{Mountains, Ceramics, and Archaeology Contribute to Management of Nuclear Waste \\ (See MRS Proceedings Volume 757)}

T. Kiess from the U.S. Department of Energy's (DOE) Yucca Mountain Project gave the keynote address in Symposium II on the Scientific Basis for NuclearWaste Management. Kiess summarized the history of the Yucca Mountain, Nev., site selection for a geological repository for spent nuclear fuel and other high-level radioactive wastes, the DOE's technical basis for selecting this site, and some anticipated future events.

J. Hanchar (George Washington Univ.), who began a session on ceramic waste forms and radiation damage in crystalline materials, described the first known zircon plutonium-doped, $\left(\mathrm{Pu}_{x} \mathrm{Zr}_{1-x}\right) \mathrm{SiO}_{4}$, single crystals of millimeter size. The rubyred crystals (see Figure 1) were synthesized with several $w \mathrm{t} \%$ of either ${ }^{238} \mathrm{Pu}$ or ${ }^{239} \mathrm{Pu}$, which are isotopes with widely different half-lives. Hanchar illustrated several macroscopic effects of severe radiation damage, including dramatic changes in color (ruby-red to light brown), as well as cracking of crystals due to volume changes caused by severe radiation damage.

A session on archaeology and waste management, organized by D.M. Strachan (PNNL), brought together experts in the seemingly disparate fields of archaeology and nuclear-waste-glass behavior. Presentations included studies of archaeologically ancient and historically significant glasses, as well as burial experiments of real and simulated radioactive-waste glasses.

In addition, a wide variety of topics were discussed throughout the symposium, including waste-form development and performance testing, engineered barriers for geological repositories, geochemical behaviors of radionuclides, naturalanalogue studies, and repository performance assessment.

Symposium Support: ANL.

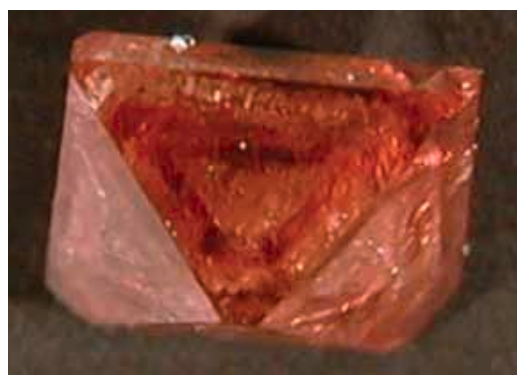

Figure 1. Single crystal of synthetic zircon, $\mathrm{ZrSiO}_{4}, \sim 4 \mathrm{~mm}$ across, with 4-6 wt $\%{ }^{238} \mathrm{Pu}$ (less than one week after synthesis). 


\section{Rapid Prototyping Finds Its Path (See MRS Proceedings Volume 758)}

Symposium LL, the third in a series on rapid prototyping (RP) technologies, highlighted a wide range of research activities in the areas of direct-write (DW), solid freeform (SFF), and microstereolithography (MSL). Sessions were held on layered manufacturing and laser sintering, solution and spray processing, and DW of microelectronics, with a few highlights on nanoscale RP and tissue engineering.

The session on nanoscale RP covered recent work on two-photon MSL (H.-B. Sun, Osaka Univ.), and on DW nanodeposition techniques using lasers (E. Nadgorny, Michigan Technical Univ.) and focused ion beams (H.D. Wanzenboeck, Vienna Univ. of Technology). The latest developments in dip-pen nanolithography (DPN) were also reported (D. Bullen, Univ. of Illinois). In the DPN technique, chemicals adsorbed onto a scanning probe are transferred selectively to a surface by diffusion while scanning in contact mode. Discussed were the design, fabrication, and optimization of active probe arrays aimed at increasing the throughput and flexibility of this process. By incorporating a thermal actuator into each probe, individual probes can be lifted from the surface to suspend the lithography process, allowing different patterns to be written by probes moving on the same path.

The tissue engineering and biomedical applications session illustrated a number of novel approaches to realization of tissue engineering scaffolds, including direct SFF by selective laser sintering (S. Das, Univ. of Michigan) and by droplet assembly (Y. Yan, Tsinghua Univ.), and indirect fabrication by casting from a rapid prototype mold (E. Sachlos, Oxford). Figure 1 shows a section through a collagenhydroxyapatite composite scaffold formed by the latter technique, illustrating the high degree of interconnecting porosity that can be achieved in the collagen matrix using this approach.

Overall, the symposium provided a snapshot on the recent advances taking place in rapid prototyping and underscored the role that these technologies might play in the future development of novel and unique 3D multifunctional structures which cannot be realized using traditional manufacturing techniques.

Symposium Support: DARPA, NSF, and ONR.

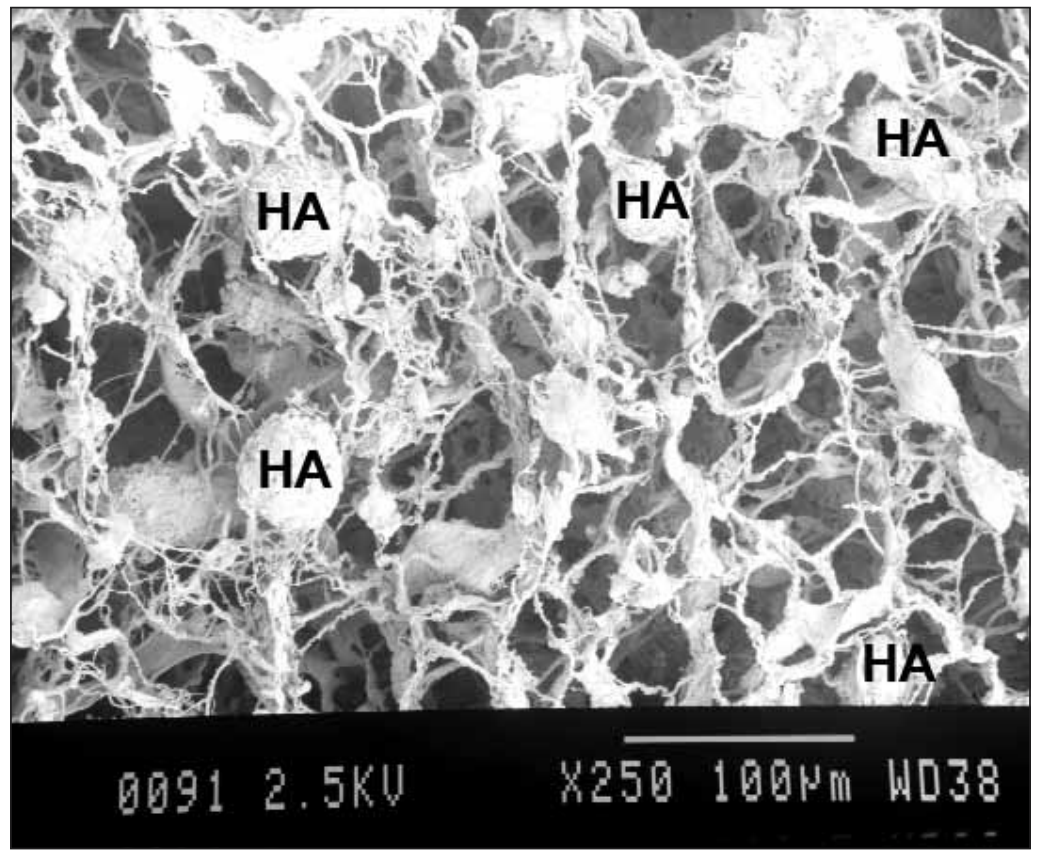

Figure 1. A collagen-hydroxyapatite composite scaffold formed by rapid prototyping. (Courtesy of E. Sachlos, N. Reis, and J.T. Czernuszka of the University of Oxford and C. Ainsley and B. Derby of the University of Manchester.)

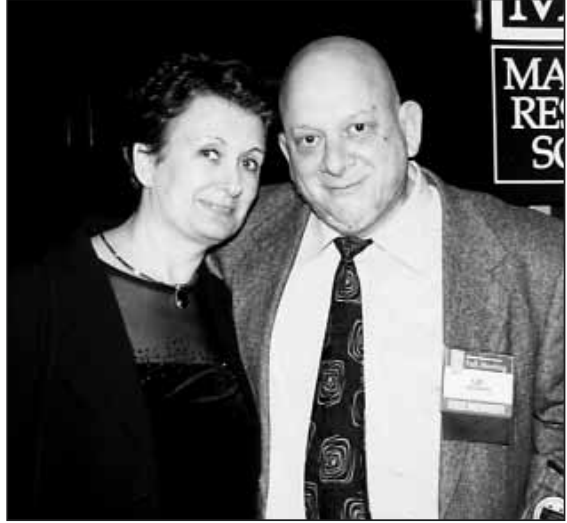

Uzi Landman (right) of Georgia Institute of Technology, 2002 MRS Medalist, poses with his wife following the awards ceremony. Later in the week, during his award talk, Landman said that the dependencies of materials properties at sufficiently small sizes may go beyond mere scaling with size, manifesting themselves in physical and chemical behavior that is new and different from that found at larger sizes. Using computational experimentation, Landman focused on nanotribology.

coatings, and using new image-analysis techniques for evaluating the data.

Symposium Support: GE and Sulzer Metco (U.S.).

\section{Retention of Undergraduate Students Key to Maintaining MSE Departments}

G.C. Farrington, President of Lehigh University, gave the keynote address in Symposium JJ on The Undergraduate Curriculum in Materials Science and Engineering (MSE). He emphasized the importance of attracting and retaining undergraduate students to materials science, and to the physical sciences in general. Without a strong undergraduate presence, MSE departments will cease to exist, he said, while research endeavors in the science departments are rapidly moving in materials. Farrington described a number of statewide collaborative initiatives to increase the effectiveness of materials education, and of the advantages of actively involving first-year students in the spring semester before they arrive on campus in the fall.

R. Snyder (Ohio State) addressed the importance of broadening the fields studied in the MSE department beyond ceramics or metallurgy in order to enlarge job opportunities for students. Many speakers talked about the need for the supporting courses, such as chemistry, physics, and math, as well as the 


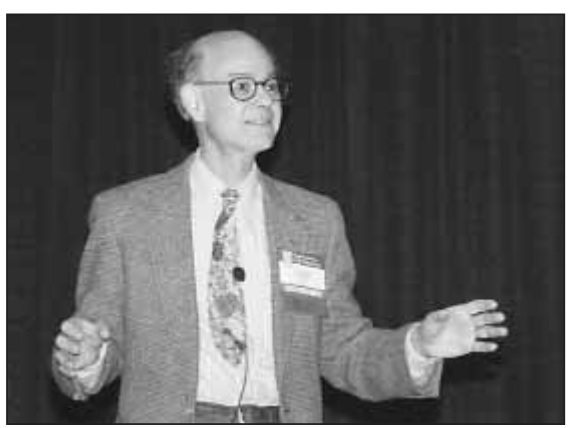

Steven Vogel, professor of biology at Duke University, presented the plenary talk, "Nature May Be Terrific, But Is She Worth Copying?"

core materials courses to be made more relevant to the students' everyday lives. K.M. Itoh described the introduction of some U.S. approaches, including student evaluation of faculty, into the Japanese curriculum at Keio University. A number of speakers described successful handson "lecture experiments" to demonstrate key materials principles: cymbals from Dalhousie University, Canada (M.A. White), the Japanese katana (Itoh), and new experiments for nanotechnology from Wisconsin University with takehome examples for faculty to try in the classroom (W. Crone).

\section{Granular Materials and Associated Technologies Explored (See MRS Proceedings Volume 759)}

Symposium MM provided an overview of a wide range of technologies and physical problems associated with materials in a granular or particulate form. Several of the examples highlighted included the importance of granular materials in xerography, suspensions, epoxy resins, ceramic materials, powder synthesis, mine detection, sand dune formation, and energy absorption technologies. These materials behave significantly different than liquids, solids, or gases and appropriate methodologies must be developed to include the particle-level features. In addition, interaction forces between the particles may significantly affect the microstructure of the material.

The symposium included experiments, numerical methods, and analytical techniques. Some of the presentations examined the effects of vibration on single particles and particle chains, wave propagation through bulk material and in granular chains, and the effect of electromagnetic fields on clustering and particle orientation. The numerical studies included some discrete element studies and the introduction of the material point method for granular materials.

Symposium Support: DOE, LANL, NASA Glenn Research Ctr., and Schlumberger.

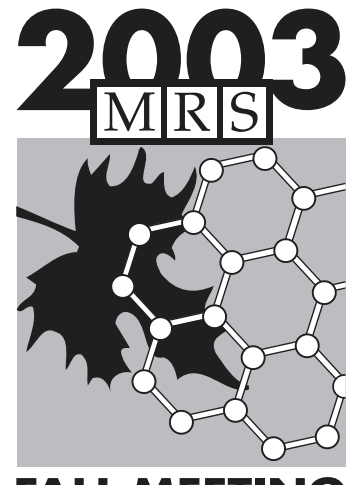

FALL MEETING

December 1-5 - Boston, MA

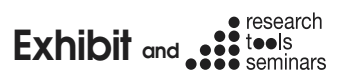

For additional meeting information, visit the MRS Web site at

\section{www.mrs.org/meetings/} or contact:

\section{$\mathrm{M}|\mathrm{R}| \mathrm{S}$}

Member Services Materials Research Society 506 Keystone Drive Warrendale, PA 15086-7573 Tel 724-779-3003 Fax 724-779-8313 E-mail: info@mrs.org
Abstract Deadlines - In fairness to all potential authors, late abstracts will not be accepted. June 5, 2003: for abstracts sent via fax or mail • June 19, 2003: for abstracts sent via the MRS Web site

\section{CALL FOR PAPERS www.mrs.org/meetings/fall2003/}

\section{SYMPOSIA}

Integrated Device Technology

A: Micro- and Nanosystems

B: Materials, Integration, and Packaging Issues for High-Frequency Devices C: Ferroelectric Thin Films XII

D: Materials and Devices for Smart Systems

E: Fundamentals of Novel Oxide/Semiconductor Interfaces

Organic, Soft, and Biological Materials

F: Biomaterials for Tissue Engineering

G: Molecularly Imprinted Materials

$\mathrm{H}$ : Biological and Bio-Inspired Materials Assembly Biomaterials for Drug Delivery

J: Interfaces in Organic and Molecular Electronics

$\mathrm{K}$ : Functional Organic Materials and Devices

Nano- to Microstructured Materials

L: Continuous Nanophase and Nanostructured Materials

M: Nontraditional Approaches to Patterning

N: Quantum Dots, Nanoparticles, and Nanowires

O: Nanostructured Organic Materials

P: Dynamics in Small Confining Systems VII

Q: Mechanical Properties of Nanostructured Materials and Nanocomposites

Inorganic Materials and Films

R: Radiation Effects and lon Beam Processing of Materials

Thermoelectric Materials 2003-

Research and Applications

: Self-Organized Processes in Semiconductor Heteroepitaxy

U: Thin Films-Stresses and Mechanical Properties X
Photonics

V: Critical Interfacial Issues in Thin Film Optoelectronic and Energy Conversion Devices

W: Engineered Porosity for Microphotonics and Plasmonics

Y: GaN and Related Alloys

Z: Progress in Compound Semiconductor Materials IIIElectronic and Optoelectronic Applications

Energy Storage, Generation, and Transport

AA: Synthesis, Characterization, and Properties of Energetic/Reactive Nanomaterials

BB: Materials and Technologies for a Hydrogen Economy

CC: Microbattery and Micropower Systems

DD: Actinides-Basic Science, Applications, and Technology

EE: Frontiers in Superconducting MaterialsNew Materials and Applications

Information Storage Materials

FF: Advanced Magnetic Nanostructures

GG: Advanced Characterization Techniques for Data Storage Materials

$\mathrm{HH}$ : Phase Change and Nonmagnetic Materials for Data Storage

Design of Materials by Man and Nature

$X: \quad$ Frontiers of Materials Research

II: The Science of Gem Materials

II: The Science of Gem Materials Materials Science II

KK: Atomic Scale Materials Design—Modeling and Simulation

LL: Quasicrystals

MM: Amorphous and Nanocrystalline Metals



\section{MEETING ACTIVITIES}

Symposium Tutorial Program

Available only to meeting registrants, the symposium tutorials will concentrate on new, rapidly breaking areas of research.

Exhibit and Research Tools Seminars

A major exhibit encompassing the full spectrum of equipment, instrumentation, products, software, publications, and services is scheduled for December 2-4 in the Hynes Convention Center, convenient to the technical session rooms. Research Tools Seminars, an educational seminar series that focuses on the scientific basis and practical application of commercially available, state-of-the-art tools, will be held again this fall.

Publications Desk

A full display of over 775 books, plus videotapes and electronic databases, will be available at the MRS Publications Desk.

Symposium Assistant Opportunities

Graduate students planning to attend the 2003 MRS Fall Meeting are encouraged to apply for a Symposium Assistant (audio-visual assistant) position.

Career Center

A Career Center for MRS meeting attendees will be open Tuesday through Thursday.

The 2003 MRS Fall Meeting will serve as a key forum for discussion of interdisciplinary leading-edge materials research from around the world. Various meeting formats—oral, poster, round-table, forum and workshop sessions-are offered to maximize participation. 